\title{
Dampening of the respiratory cytokine storm is promoted by inhaled budesonide in patients with
}

\section{early COVID-19}

Jonathan R Baker ${ }^{1}$, Mahdi Mahdi ${ }^{2,3}$, Dan V Nicolau Jr. ${ }^{3,4,5}$, Sanjay Ramakrishnan ${ }^{2,3,6}$, Peter J Barnes ${ }^{1}$, Jodie L Simpson ${ }^{7}$, Steven P Cass ${ }^{2,3}$, Richard EK Russell ${ }^{2,3}$, Louise E Donnelly ${ }^{1},{ }^{*}$ Mona Bafadhel ${ }^{2,3}$

${ }^{1}$ National Heart and Lung Institute, Imperial College London, London, United Kingdom

${ }^{2}$ National Institute for Health Research (NIHR) Oxford Biomedical Research Centre (BRC), United Kingdom

${ }^{3}$ Nuffield Department of Medicine, University of Oxford, United Kingdom

${ }^{4}$ UQ Centre for Clinical Research, The University of Queensland, Brisbane, Australia

${ }^{5}$ School of Mathematical Sciences, Queensland University of Technology, Brisbane 4000 Australia

${ }^{6}$ School of Medical and Health Sciences, Edith Cowan University, Perth, Australia

${ }^{7}$ School of Medicine and Public Health, Priority Centre for Healthy Lungs, University of Newcastle, Australia

${ }^{*}$ Corresponding Author:

Professor Mona Bafadhel, Nuffield Department of Clinical Medicine, University of Oxford.

Email: mona.bafadhel@ndm.ox.ac.uk 


\section{Summary}

Vaccinations against SARS-CoV-2 are effective in COVID-19. However, with limited vaccine access, vaccine hesitancy and variant breakthroughs, there is still a need for effective and safe early treatments. Two community-based clinical trials of the inhaled corticosteroid, budesonide, have recently been published showing and improvement in patients with COVID-19 treated early with budesonide $e^{1,2}$. To understand mechanistically how budesonide was beneficial, inflammatory mediators were assessed in the nasal mucosa of patients recruited to the Steroids in COVID (STOIC ${ }^{1}$ ) trial and a cohort of SARS-CoV-2 negative individuals. Here we show that in early COVID-19, elevation in viral response proteins and Th1 and Th2 inflammation occurs. Longitudinal sampling in the natural course of COVID-19 showed persistently high interferon levels and elevated concentrations of the eosinophil chemokine, CCL11. In patients who deteriorate, the initial nasal mucosal signal is characterised by a marked suppression of the early inflammatory response, with

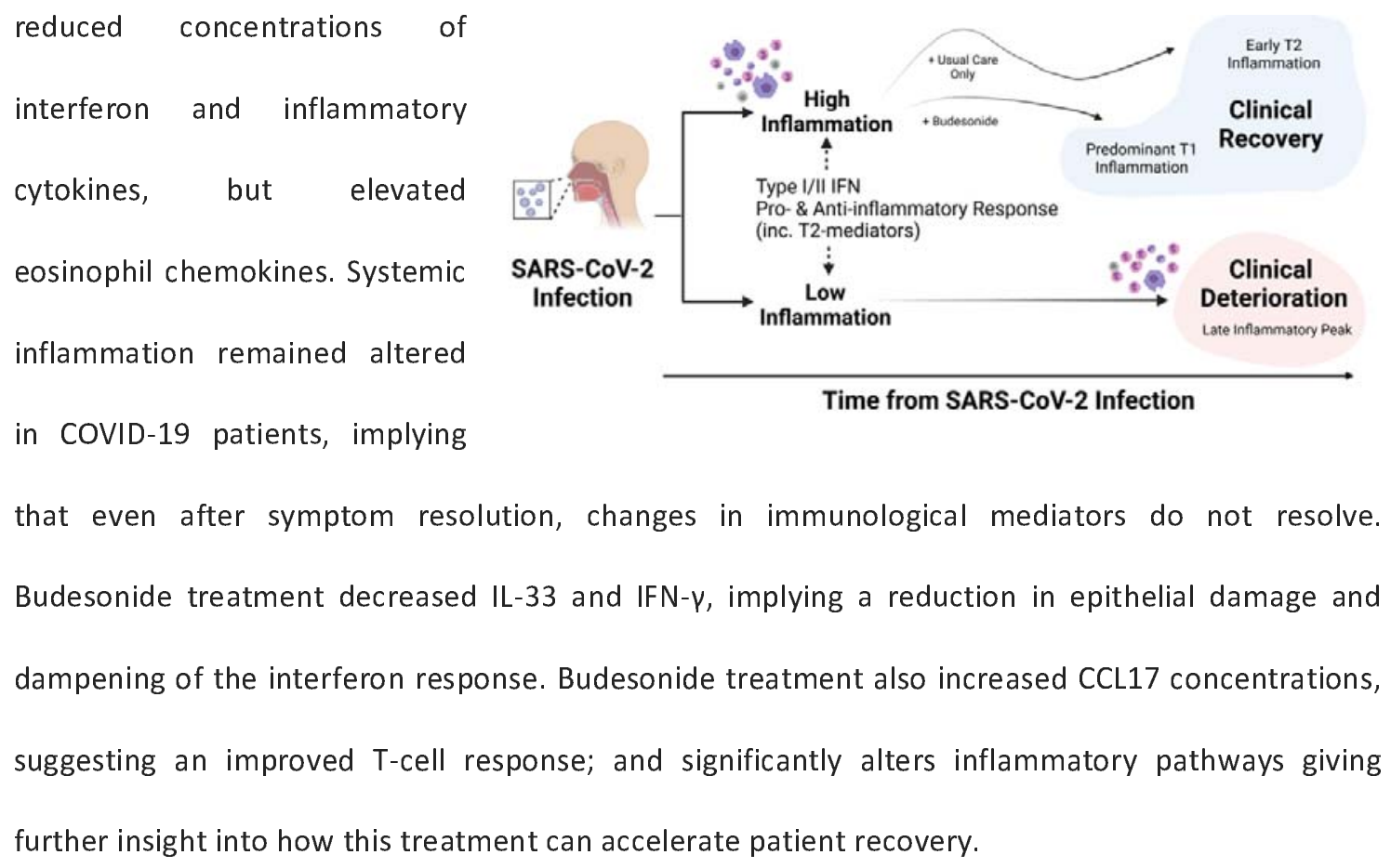

Time from SARS-CoV-2 Infection

that even after symptom resolution, changes in immunological mediators do not resolve. Budesonide treatment decreased IL-33 and IFN- $\gamma$, implying a reduction in epithelial damage and dampening of the interferon response. Budesonide treatment also increased CCL17 concentrations, suggesting an improved T-cell response; and significantly alters inflammatory pathways giving further insight into how this treatment can accelerate patient recovery. 


\section{Introduction}

There has been a rapid increase in the understanding of the inflammation that occurs following SARS-CoV-2 infection ${ }^{3}$. Largely this has investigated the immune response in patients with severe infection that required hospitalisation ${ }^{4}$. In the investigation of early COVID-19, studies have focussed on inflammation caused by the systemic immune response ${ }^{5}$ whilst the inflammatory response in the airway of patients remains unknown, in part due to the risk of contagion through aerosolization of the virus. The airway inflammatory response to common respiratory viruses in healthy individuals ${ }^{6}$ and in patients with chronic airways disease has been extensively studied ${ }^{7,8}$. Inhaled corticosteroids (ICS) are often prescribed in patients with asthma and chronic obstructive pulmonary disease (COPD) to reduce the risk of exacerbations which are usually mediated by respiratory viruses ${ }^{9-11}$. During the ongoing COVID-19 pandemic, it has been reported that patients with asthma and COPD are less likely to be hospitalised with severe COVID-19 12,13 . The reasons for this are unclear but in patients with asthma, the use of ICS two weeks prior to hospitalisation for severe COVID-19 was associated with better clinical outcomes ${ }^{14}$. Our recent STOIC study investigated inhaled budesonide, a corticosteroid, as a treatment for early COVID-19 infection with positive findings in improvement in self-reported symptom recovery, with fewer patients experiencing adverse outcomes and less symptom persistence ${ }^{1}$. This finding has now been replicated in a large Phase 3 efficacy trial ${ }^{2}$, but has yet to attract global adoption. The mechanism for how ICS can improve early COVID-19 infection is however currently unknown.

Here, we report the nasal mucosal inflammatory response in patients with early COVID-19 disease and examine the evolution of inflammation in the natural course of COVID-19. We also identify how inflammation in the airway can predict illness severity and investigate the effect of inhaled budesonide upon the respiratory mucosa in early COVID-19 disease. Finally, we show using network analysis how inhaled budesonide can resolve the exaggerated inflammatory response seen in early COVID-19 infection and promote resolution to health. 


\section{Results}

The STOIC study recruited 144 participants aged 18-79 (mean 45) years, of which there was 140 available nasal mucosal samples at visit 1 (day 0) and 122 samples at visit 3 (day 14). At day 28 (visit 4), whole blood was collected from 124 participants. The demographics of the healthy volunteers are presented in supplementary table S1. The demographics of the STOIC study participants are as previously published ${ }^{1}$.

\section{The respiratory inflammatory response in early COVID-19 is different to health}

Firstly, we examined the inflammatory profile of nasal mucosal fluid in healthy controls $(n=20)$ and early (median duration of symptoms 3 days) COVID-19 infection ( $n=140$ ). (Figure 1A). We found that 14 mediators were elevated in COVID-19 infected patients compared to controls. These were a mixture of Th1 cytokines (IL-2, IL-12, TNF- $\alpha$, IFN- $\psi$ ), Th2 cytokines (IL-2, IL-4), interferon/interferon response proteins (IFN- $\alpha 2 \mathrm{a}$, IFN- $\beta$, IFN- $\gamma$, CXCL10, CXCL11) and chemokines (CCL3, CCL4, CCL11, CCL13) (Figure 1B). An altered T-cell response with significantly reduced levels of TSLP and CCL17 was also found and reduced CCL2 levels implying impaired monocyte recruitment (Figure 1B). There were also lower levels of VEGF, as has been previously described in severe hospitalised COVID-19 patients $^{15}$ (Figure 1B). Some mediators were unaltered (IL-1 $\beta$, IL-33, CCL24, CCL26, IL-5, GM-CSF and IL-10), suggesting less activation during early COVID-19 (Figure 1B). CXCL8 was unchanged between health and early COVID-19, but this may reflect assay sensitivity as CXCL8 was repeatedly over the limit of detection (occurred in $35 \%$ of healthy control and $45 \%$ of early COVID-19 samples).

Interferon and eosinophil chemotactic proteins remain elevated over the course of early COVID-19

We examined nasal mucosal inflammation during the course of disease (i.e., in the UC study arm, $\mathrm{n}=60$ ), examining paired samples from this population at visit 1 and visit 3 (Figure 1C). Over the course of 14 days, CXCL9, CXCL10, CXCL11, IL-12, IL-10, IL-2, IFNa2a, CCL2, CCL3, CCL4, IL-6, IL-4, CCL13 and TNF- $\alpha$ all significantly reduced. Of the 14 mediators elevated in early COVID-19 compared 
medRxiv preprint doi: https://doi.org/10.1101/2021.10.26.21265512; this version posted October 27, 2021. The copyright holder for this preprint (which was not certified by peer review) is the author/funder, who has granted medRxiv a license to display the preprint in perpetuity.

It is made available under a CC-BY-ND 4.0 International license .

to healthy controls, 11 of these mediators in the course of early COVID-19 infection decreased over time (CCL3, CCL4, TNF- $\alpha$, IL-6, CCL13, IL-4, IFN- $\alpha 2 a$, CXCL10, CXCL11, IL-2, IL-12). CCL11, IFN- $\beta$ and IFN- $\gamma$ did not significantly change between visit 1 and 3 and remained elevated after 14 days compared to health. VEGF, TSLP and CCL17 levels were unchanged over time, remaining lower than health, but CCL2 and IL-10 levels significantly reduced (Figure 1C). IL-1ß, CXCL8, IL-33, CCL24, CCL26, IL-5, GM-CSF did not show any changes between the two study visits over time. In the nasal mucosa of participants in the study, we also assessed a further 4 mediators, of which PDGFA, CCL5 and TGF$\beta 1$ were unchanged over time; whilst CXCL9 levels reduced (Figure 1D).

\section{Inhaled budesonide leads to reduction of Type 2 cytokines over the course of early COVID-19}

The STOIC study showed that inhaled budesonide treatment, taken for a mean duration of 7 days, reduced the number of COVID-19 patients who deteriorate and reduces the time to clinical recovery ${ }^{1}$. To investigate the potential mechanisms behind this finding we examined the concentrations of 30 mediators in paired visit 1 and visit 3 samples in the inhaled budesonide arm of the STOIC trial ( $n=62$, Figure 1E). Of the mediators examined, those that were different to the natural course of early COVID-19 disease (as described above from the UC arm), IL-33 and IFN- $\gamma$ were significantly reduced, CCL17 concentrations were significantly increased, and CCL13 was no longer significantly reduced between the two visits (Figure 1F). The differences between UC and BUD, showed that IL-33 was significantly reduced and CCL17 significantly elevated in the BUD arm (supplementary figure S2). As all visit 1 samples were taken prior to treatment, we also compared both the UC study arm and BUD study arm visit 3 samples to all visit 1 samples to assess the return to health. We found that following treatment with inhaled budesonide, CCL5 was significantly reduced, and GM-CSF was not reduced; whilst concentrations of IL-2 and IL-4 were sustained, despite falling in the UC study arm (supplementary figure S3). Changes in the levels of these mediators may therefore help to explain differences in the recovery of these patients and play a part in the disease course of COVID-19. 


\section{SARS-CoV-2 viral load correlation with nasal mucosal inflammation differs from systemic} inflammation

As previously reported viral load correlates with type I interferon expression and inflammatory markers and chemokines in the blood ${ }^{16}$. We thus examined whether there was a similar correlation with the nasal mucosa. SARS-CoV-2 viral load and nasal mucosal mediator measurements were available in 122 paired samples at study entry (day 0). We found that IFN- $\alpha 2$ a, CXCL10, CXCL11, IL12, CCL2 and IL-6 correlated with viral load (supplementary table S2). These show a different pattern of markers, with some overlap, to those measured in serum ${ }^{16}$ and may reflect differences between local and systemic inflammation, perhaps related to the number of viral particles.

\section{Despite clinical recovery, nasal mucosal inflammation does not completely return to normal}

To assess whether the inflammation associated with SARS-CoV-2 infection declined over time to levels in health, we compared our healthy cohort to the visit 3 samples of the UC and BUD study arms (Figure 2A). In both UC and BUD study arms, compared to healthy controls, IL-2, CCL11, IL-4, TNF- $\alpha$, IFN- $\beta$, IFN- $\gamma$ and CXCL11 all remained significantly elevated, whilst CCL3, CCL4, IL-6, CCL13, IFN- $\alpha 2 a, C X C L 11$ and IL-12 reduced back to comparable healthy concentrations (Figure 2B). CCL2 and TSLP remained significantly lower than health irrespective of the study arm. Even though the concentration of CCL17 was increased in the BUD study arm over time, these did not return to expected healthy concentrations. Interestingly, IL-10 significantly decreased over time in the UC study arm but not in the BUD study arm, suggesting a sustained anti-inflammatory response in patients treated with inhaled budesonide (Figure 2B). It should be noted that the time to selfreported clinical recovery in the study was a mean of 9 days, suggesting that although certain mediators reduce during the disease, multiple mediators remain increased within the nasal mucosa and significantly past the time-point of clinical recovery. 


\section{A bi-phasic peak of inflammation is seen in the course of COVID-19, which is supressed by inhaled budesonide}

Spline best-fit curve analysis was performed to assess kinetic inflammatory changes over the disease course of early COVID-19 infection (UC study arm) and with ICS intervention (BUD study arm). The spline analysis considers the timing of the first symptom and gives an indication of peak of inflammation and resolution. In general, peak inflammation occurred early in the disease course. Additionally, IL-4, IL-12, IL-2, CXCL10, PDGFA and IFN- $\alpha 2$ a kinetic changes were similar between natural course of early COVID-19 and inhaled budesonide. However, inhaled budesonide supressed kinetic inflammation and in particular a secondary increase in inflammation beyond day 15 (as seen with TNF- $\alpha$, GM-CSF and CCL5). Interestingly, IFN- $\gamma$ increased following inhaled budesonide at day 15 following symptom onset (Figure $2 \mathrm{C}-2 \mathrm{E}$ and supplementary figure $\mathrm{S4}$ ).

\section{The early nasal mucosal inflammatory pattern can predict patients that deteriorate following COVID-19 infection}

Eleven participants met the primary outcome for deterioration in the clinical trial (defined as needing urgent care assessment, emergency care consultation and/or hospitalisation), with $70 \%$ needing oxygen treatment. Spline mediator analysis was performed to investigate the kinetics of nasal mucosal inflammation from the first 7 days of symptom onset. Specifically, IL-2, IL-12, IL-4, GM-CSF, IL-10, IL-5, IFN- $\gamma$ did not increased, whilst CXCL9, CXCL10, TNF- $\alpha$ and IFN- $\beta$ showed peaks much higher and earlier than samples from participants without clinical deterioration following COVID-19 infection (supplementary figure S5). Comparison of mediators from healthy controls and participants that met the primary outcome showed that CCL3 TNF- $\alpha$, IFN- $\alpha 2 a$, IFN- $\beta$, CXCL10, CXCL11, CCL11 and CCL24 were all significantly increased. CCL3, TSLP, CCL17, IL-10, GM-CSF and IL33 were significantly reduced (Figure $\mathbf{3 A}$ ). To try and understand why these participants met the primary outcome, we examined mediator concentrations in these participants against health (Figure 
3B). We found that nasal mucosal inflammation in participants who reached the primary outcome, did not respond to SARS-CoV-2 infection in the same manner. There was no increase in CCL4, IL-12, IFN- - , IL-4, CCL13, IL-2, and IL-6, suggesting an impaired inflammatory response. Additionally, reduction in IL-10, IL-33 and GM-CSF occurred in this group compared to no change in the early COVID-19 cohort. VEGF did not reduce in those who met the primary outcome opposed to those with early COVID-19. Interestingly, CCL24 levels were increased in participants who met the primary outcome, confirming that a high eosinophilic phenotype is associated with severe disease.

Comparison of mediators in participants with COVID-19 and participants with COVID-19 who clinically deteriorated was performed to understand any aberrant immune response during the early part of SARS-CoV-2 infection. Interestingly, all mediators that were significantly different (GM-CSF, IL-10, IL-12, IL-2, IFN- $\alpha 2 \mathrm{a}$ and IL-33) were downregulated in worsening disease suggesting at the early stages of the disease a blunted response to infection occurs in patients who then deteriorate (Figure $3 \mathrm{C}-\mathrm{H}$ ). In one participant, needing critical care support (UC study arm), longitudinal nasal sampling was available giving insight into course of the disease in a more severe patient. Interestingly, the interferon response proteins, CCL5, CXCL9 and CXCL10 remained elevated and CXCL11 fell. Concentrations of the inflammatory markers IL-1 $\beta$, IL-33 and IL-6 also increased over time in this participant (Figure 31, supplementary figure 6).

There is persistent systemic inflammation following COVID-19 infection, but this is attenuated by inhaled budesonide

Serum inflammatory mediators up to 35 days after initial infection remained elevated compared to healthy controls (Figure 4A-F, supplementary figure 7). This included higher concentrations of TNF$\alpha, I L-8$ and the family of eosinophil chemotactic proteins (CCL11, CCL24, CCL26) and may be a driver for long COVID. This systemic inflammation was supressed to a greater degree by inhaled budesonide, for CCL11, TNF- $\alpha$ and IL-33. 


\section{Effect of inhaled budesonide treatment on mediator expression following COVID-19 demonstrated} normalised T2 airway and circulatory response

Network analysis of inflammatory mediators in the nasal mucosa and serum were performed (Figure 5). A rapid onset anti-inflammatory response (IL-10) and T2 inflammatory (CCL11 and CCL24) response with co-existent inflammation (IL-6 and CXCL8) can be seen in early COVID-19 infection (Figure 5A-1). Two weeks after initial infection, the natural course of COVID-19 infection shows persistent nasal mucosal inflammation with an exaggerated T2 inflammatory response (CCL11 and IL-5) and a sustained pro-inflammatory response (Figure 5A-2). Network analysis demonstrated that there was $72 \%$ overlap between the inflammatory response at an early timepoint in COVID-19 infection and at the later timepoint, indicating persistent inflammation of similar pathways. Following inhaled budesonide treatment, the nasal mucosal response is different with an increased anti-inflammatory response (IL-10) and alarmins (IL-33 and TSLP), but a reduced T2 inflammatory response suggesting normalisation of the anti-viral immune response with suppression of the T2 hyper-inflammatory response we have seen following COVID-19 infection. The overlap between the inflammatory response at an early timepoint in COVID-19 infection and at the later timepoint was only $27 \%$ in the BUD study arm. Network analysis of serum mediators performed between 28 and 35 days after initial infection in the UC study arm shows persistent IFN- $\alpha 2 a$, CCL11 and CCL2 (Figure 5B-1). There was only a $30 \%$ overlap with the serum of participants that had been treated with inhaled budesonide (Figure 5B-2). These findings suggests that inhaled budesonide modulates the inflammatory pathways in the upper respiratory tract and circulation following COVID-19 infection. 


\section{Discussion}

In this study, we examined the inflammatory effect of SARS-CoV-2 upon the upper airway at a very early timepoint during the course of COVID-19 infection ${ }^{1}$ and followed patients over the evolutionary course of COVID-19 infection. Our study provides a unique mechanistic insight into the host respiratory immune and inflammatory response to early COVID-19 infection and following a therapeutic intervention with benefit. Notably, studies thus far have examined only a small number of airway samples from severe and hospitalised patients, late in the disease course ${ }^{17,18}$ or measured the immune response in the circulation ${ }^{19}$. Moreover, these studies focus on transcriptional analysis which may not fully recapitulate the protein environment. In contrast this study is the first to examine protein levels in the upper respiratory tract of early COVID-19; thus providing a unique mechanistic insight into the host respiratory immune and inflammatory response to early COVID-19 infection and subsequent therapeutic intervention with benefit.

Our study has shown, unlike previously assumptions ${ }^{20}$, that there is a vigorous and early immune response in the upper airway in patients who develop COVID-19 infection. This response, in comparison to healthy controls, is an early combined Type I and Type II interferon response, proinflammatory response and anti-inflammatory response. Interestingly, early in COVID-19 there is also a T2 immune response, mediated mainly by CCL11 and IL-4. This early COVID-19 innate cytokine immune response will lead to recruitment of eosinophils, NK cells and macrophages and is an immune response similar to that which is seen with other respiratory viruses ${ }^{21}$.

We have also shown that in patients in whom there was a clinical deterioration following SARS-CoV2 infection, the initial inflammatory response in the airway is blunted with an impaired inflammatory response and reduced concentrations of IL-2, IL-33, IL-12 and IFN- $\alpha 2 \mathrm{a}$. A blunted circulatory interferon response has been previously shown to be a feature of severe COVID-19 infection ${ }^{22}$. As our sampling was in early COVID-19 infection, these findings suggest that an early impaired interferon response to COVID-19 can highlight an important aspect of diagnosis and treatment; and 
is a potential biomarker to predicting patients at risk of deterioration who warrant further early treatment. Identification of patients early and at risk of deterioration will markedly improve clinical care for patients.

Interestingly, CCL24 was the only mediator increased in patients who deteriorated following COVID19 infection. The CC subfamily of eosinophil chemotactic proteins (CCL11, CCL24 and CCL26), along with IL-5, GM-CSF and CCL5 are responsible for lung recruitment and activation of eosinophils ${ }^{23}$. Recruitment of eosinophils to the lung, is the most likely explanation for the reduced circulatory number of eosinophils reported as part of the clinical picture of severe COVID-19 infection ${ }^{24}$. Furthermore, inhaled corticosteroids are recognised to be therapeutically effective in patients with an eosinophilic phenotype of airways disease ${ }^{25}$. The elevation of CCL24 in patients that subsequently deteriorated in this study validates that the high eosinophilic phenotype, albeit measured in the plasma previously is associated with severe disease, as previously described ${ }^{16}$.

Our study is also the first to demonstrate that there is ongoing inflammation in the circulation, over 4 weeks after SARS-CoV-2 infection, with elevated levels of IL-2, IL-6, CXCL8, CCL13, TNF- $\alpha$ and interestingly CCL11, CCL24 and CCL26. Persistent symptoms following COVID-19 infection has been recently been identified as an emerging problem ${ }^{26}$ and our study may implicate how this may be underlined by persistent inflammation. To note, the airway and peripheral blood immune profile in severe COVID-19 infection is different ${ }^{27}$. It is therefore plausible that the identification of inflammatory mediators in the circulation is delayed compared to assessing samples proximal to the site of infection. The STOIC study showed that persistence of symptoms was significantly lower in patients that were taking inhaled budesonide suggesting that early inhaled corticosteroid treatment can improve symptoms of COVID-19 and may help to prevent the effects of long COVID. We found that TNF- $\alpha$ and CCL11 were significantly lower in the systemic circulation in patients that had been treated with inhaled budesonide compared to usual care, suggesting that these mediators could be key for future clinical targets. Patients with long COVID commonly report symptoms of 
breathlessness ${ }^{28}$, whilst asthma has been found to be the only pre-existing comorbidity with an independent association of long $\operatorname{COVID}^{28}$. Whether there is a pre-existing host or exaggeration of the T2 phenotype that leads to long COVID warrants further investigation.

Due to the nature of the STOIC study design ${ }^{1}$, we were able to examine the kinetics of inflammation amongst patients with early COVID-19 and in patients that received inhaled budesonide as a treatment intervention. We found that in early COVID-19 there is down-regulation of inflammation, but this does not return to levels seen in health. Examination of the mediator temporal relationship showed that there was often a bi-phasic peak of inflammatory mediators, which is staggered and persists over time. Importantly however, we found that in patients taking inhaled budesonide, the inflammatory peak was attenuated for TNF- $\alpha$, GM-CSF, and CCL5 and promoted for IFN- $\gamma$. IFN- $\gamma$ is an important promoter of anti-viral immunity ${ }^{29}$ playing a role in the inhibition of viral replication in cells $^{30}$, suggesting another mechanism for the efficacy of ICS. Following inhaled budesonide treatment, the nasal mucosal response is different with an anti-inflammatory response (IL-10), an increase in alarmins (IL-33 and TSLP) and a reduced T2 inflammatory response which suggests the promotion of a normal anti-viral and suppression of the exaggerated T2 inflammatory response.

The initial observation of a significant under-representation of patients with obstructive lung disease (asthma and COPD) with severe COVID-19 infection, with the knowledge that ICS treatment is routinely used to prevent viral exacerbations was the founding hypothesis for the STOIC trial ${ }^{1}$. The respiratory epithelium, especially the nasal mucosa exhibits the most abundant expression of ACE2 receptors important for SARS-COV-2 binding ${ }^{31}$. ICS have been shown to reduce ACE2 receptor expression in-vitro ${ }^{32}$ and in-vivo ${ }^{33}$, plus have previously been shown to inhibit viral replication in-vitro and reduce inflammation following rhinovirus infection ${ }^{34}$. The potential therapeutic effect of ICS in other respiratory virus infections have previously been explored ${ }^{35}$. ADAM17 is a necessary protease for ACE2 receptor availability and also mediates the release of IL- 6 and TNF- $\alpha^{36}$. ADAM17 gene expression is reduced following ICS therapy ${ }^{33}$. ICS reduce inflammation by decreasing the 
medRxiv preprint doi: https://doi.org/10.1101/2021.10.26.21265512; this version posted October 27, 2021. The copyright holder for this preprint (which was not certified by peer review) is the author/funder, who has granted medRxiv a license to display the preprint in perpetuity. It is made available under a CC-BY-ND 4.0 International license.

transcription of inflammatory cytokines including IL-4, IL-5 and GM-CSF and the chemokines, CCL11 and $\mathrm{CCL}^{35}$. These pathways form part of a Th2 inflammatory response that we have seen in our study of early COVID-19, and particularly in patients that deteriorate. Our findings suggest that we now have a therapeutic mechanism of how inhaled corticosteroids are an effective treatment in early COVID-19 infection. 
medRxiv preprint doi: https://doi.org/10.1101/2021.10.26.21265512; this version posted October 27, 2021. The copyright holder for this preprint (which was not certified by peer review) is the author/funder, who has granted medRxiv a license to display the preprint in perpetuity.

It is made available under a CC-BY-ND 4.0 International license .

Figure 1

A
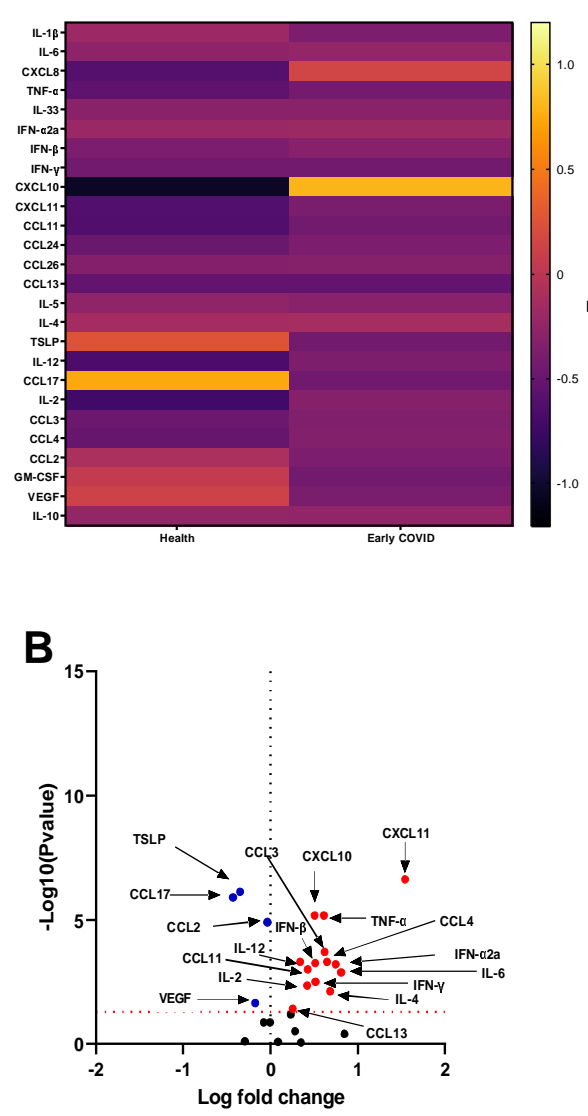

C

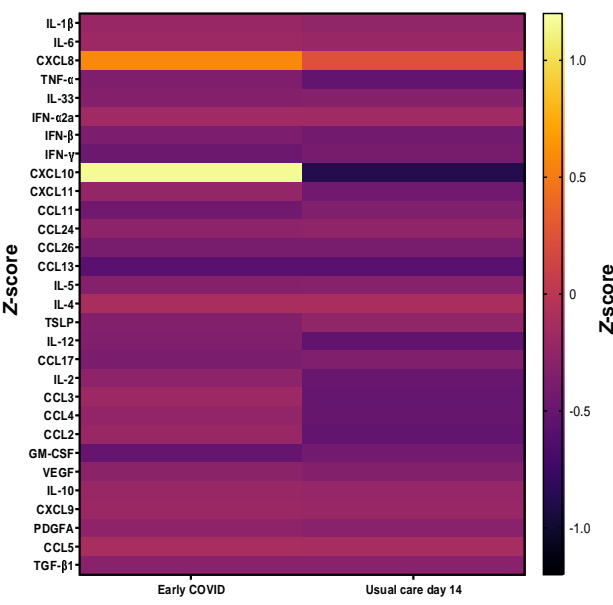

D

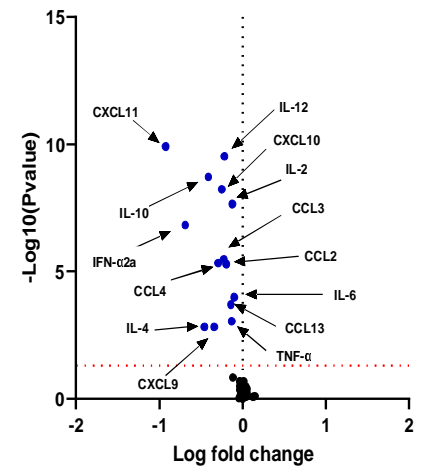

E

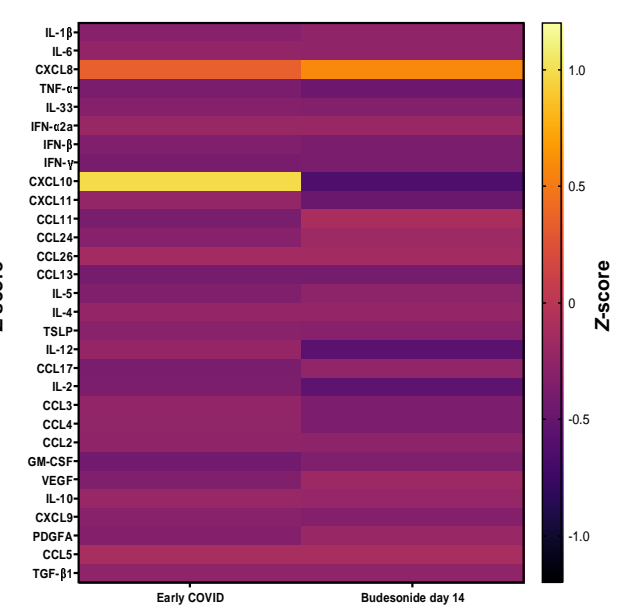

$\mathbf{F}$

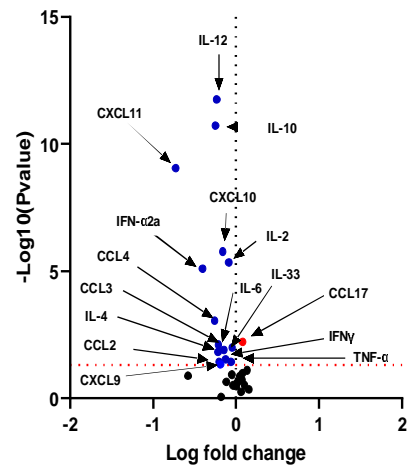

Figure 1. Immunological features of the nasal mucosa in patients with early COVID-19 over time in the STOIC

study A) Heatmap and B) volcano plot of 26 nasal mediators from 20 healthy individuals and 140 patients with community based early COVID-19. C) Heatmap and D) volcano plot of 30 nasal mediators from patients with community based early COVID-19 at visit 1 (Day 0) time point of enrolment into trial and visit 3 (Day 14) in the usual care $\operatorname{arm}(n=60)$. E) Heatmap and F) volcano plot of 30 nasal mediators from patients with community based COVID-19 at visit 1 (Day 0) time point of enrolment into trial and visit 3 (Day 14) in the budesonide arm $(n=62)$. Horizontal dotted line on volcano plots depict cut-off for statistical significance, the vertical dotted line represents cut-off point determining whether mediator levels were higher (right, red) or lower (left, blue) for

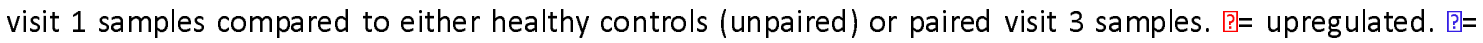
downregulated. Data were analysed using Mann-Whitney t-test or Wilcoxon matched pairs signed rank test. 
medRxiv preprint doi: https://doi.org/10.1101/2021.10.26.21265512; this version posted October 27, 2021. The copyright holder for this preprint

(which was not certified by peer review) is the author/funder, who has granted medRxiv a license to display the preprint in perpetuity.

It is made available under a CC-BY-ND 4.0 International license.

Figure 2

A

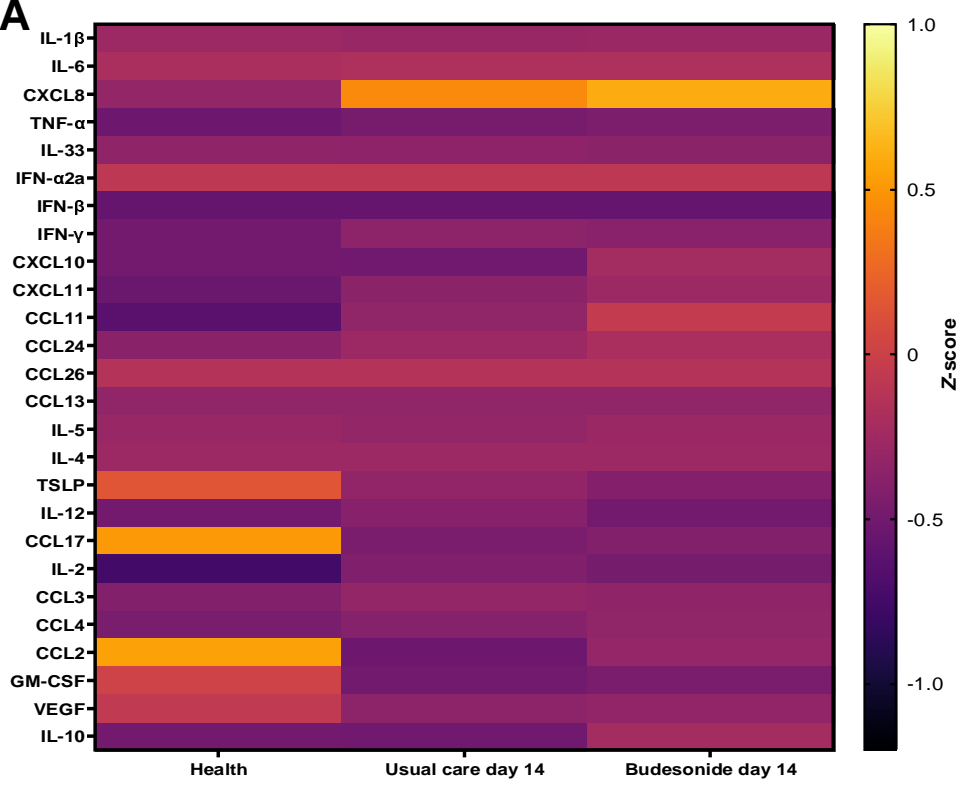

C

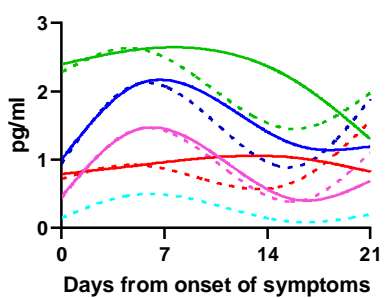

$-\cdots$ TNF- $\alpha$

-.. IL-2

-.. IL-12

- . GM-CSF

- . IL-4

- TNF- $\alpha$ Bud

- IL-2 Bud

- GM-CSF Bud

- IL-12 Bud

IL-4 Bud
D

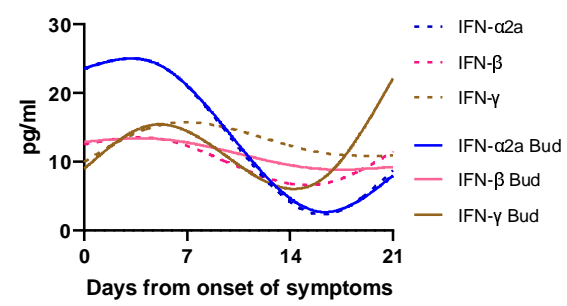

B

\begin{tabular}{|ccc|}
\hline Mediator & $\begin{array}{c}\text { Change from health at 14 } \\
\text { days } \\
\text { (Usual care) }\end{array}$ & $\begin{array}{c}\text { Change from health at 14 days } \\
\text { (Budesonide) }\end{array}$ \\
\hline IL-2 & Up & Up \\
\hline CCL11 & Up & Up \\
\hline CXCL11 & Up & Up \\
\hline IFN- $\beta$ & Up & Up \\
\hline IFN- $\gamma$ & Up & Up \\
\hline IL-4 & Up & Up \\
\hline TNF- $\alpha$ & Up & Up \\
\hline IL-10 & Down & No change \\
\hline CCL2 & Down & Down \\
\hline CCL17 & Down & Down \\
\hline TSLP & Down & Down \\
\hline
\end{tabular}

\section{E}

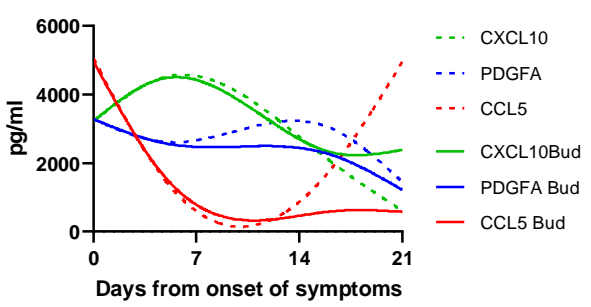

Figure 2. Temporal changes in mediator levels in usual care and budesonide arm. A) Heatmap of 26 nasal mediators from

20 healthy individuals compared to samples at day 14 post recruitment (visit 3) from usual care study arm ( $\mathrm{n}=60$ ) and budesonide study arm ( $n=62)$. B) List of significantly altered mediators compared from health at day 14 time point in both usual care and budesonide treated arm. C-E) Longitudinal analysis of mediator profiles in the usual care and budesonide arm displayed as representative best fit curves by smoothed spline analysis. 
medRxiv preprint doi: https://doi.org/10.1101/2021.10.26.21265512; this version posted October 27, 2021. The copyright holder for this preprint (which was not certified by peer review) is the author/funder, who has granted medRxiv a license to display the preprint in perpetuity.

It is made available under a CC-BY-ND 4.0 International license .

Figure 3

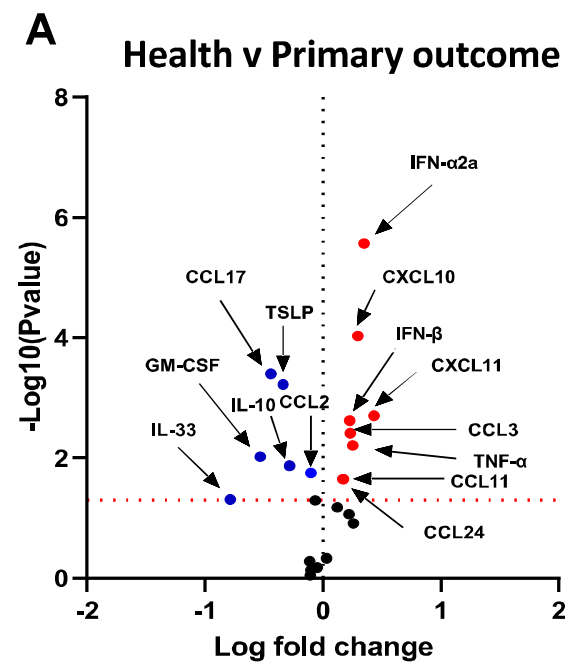

\begin{tabular}{|c|c|c|}
\hline Mediator & $\begin{array}{l}\text { Comparison between } \\
\text { health and early } \\
\text { coviD-19 in whom } \\
\text { primary outcome was } \\
\text { not met }\end{array}$ & $\begin{array}{c}\text { Comparison between } \\
\text { health and early COVID-19 } \\
\text { in whom primary outcome } \\
\text { was met }\end{array}$ \\
\hline CCL4 & Up & No change \\
\hline IL-12 & Up & No change \\
\hline IFN-y & Up & No change \\
\hline IL-4 & Up & No change \\
\hline CCL13 & Up & No change \\
\hline IL-2 & Up & No change \\
\hline IL-6 & Up & No change \\
\hline IL-10 & No change & Down \\
\hline IL-33 & No change & Down \\
\hline GM-CSF & No change & Down \\
\hline CCL24 & No change & Up \\
\hline VEGF & Down & No change \\
\hline
\end{tabular}

C

D

E

$\mathbf{F}$

G

H

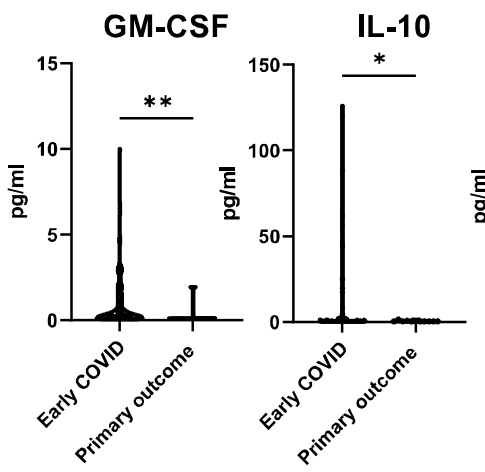

IL-12

IL-2
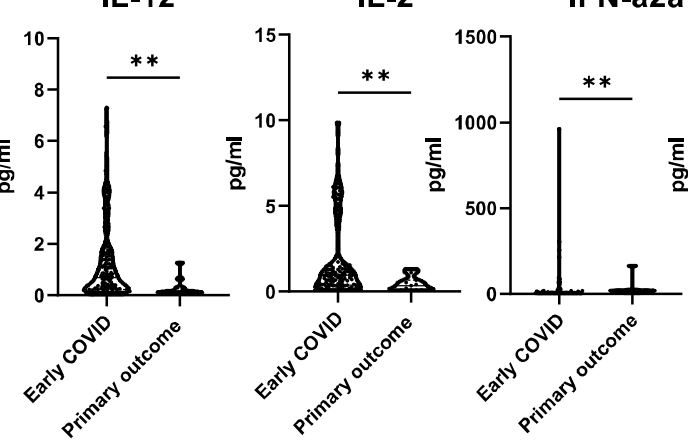

IL-33

\begin{tabular}{|c|c|}
\hline Mediator & $\begin{array}{c}\text { Change after } 14 \\
\text { days }\end{array}$ \\
\hline $\mathrm{IL}-1 \beta$ & Up \\
\hline IL-6 & Up \\
\hline It-33 & Up \\
\hline IFN-V & up \\
\hline CCL11 & up \\
\hline CCL24 & up \\
\hline CCL26 & Up \\
\hline TSLP & up \\
\hline CCL17 & Up \\
\hline CCL5 & Up \\
\hline GM-CSF & Up \\
\hline CxC19 & Up \\
\hline VEGF & Up \\
\hline CCL13 & No change \\
\hline Cxc110 & No change \\
\hline CXCL18 & No change \\
\hline IL-4 & No change \\
\hline TGF- $\beta$ & No change \\
\hline TNF- $\alpha$ & Down \\
\hline
\end{tabular}

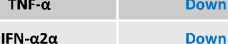

IFN-B Down

CXCL11

Down

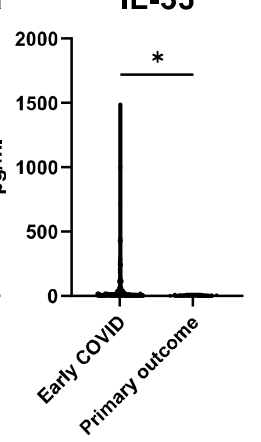

\begin{tabular}{|c|l|}
\hline CXCL11 & Down \\
\hline IL-5 & Down \\
\hline IL-12 & Down \\
\hline IL-2 & Down \\
\hline CCL3 & Down \\
\hline CCL4 & Down \\
\hline CCL2 & Down \\
\hline IL-10 & Down \\
\hline PDGFA & Down \\
\hline
\end{tabular}

Figure 3. Alterations in nasal mucosal inflammation in whom early COVID-19 clinically worsens A) Volcano plot of 26

nasal mediators from 20 healthy individuals and 11 patients in who the primary outcome of the study was met; 国= significantly upregulated. 圆= significantly downregulated. B) Comparison table of significantly altered mediators from nasal samples comparing health $(n=20)$, early COVID-19 ( $n=129)$ without deterioration and COVID-19 with deterioration $(n=11)$.

C-H) Significantly altered mediators at visit 1 from patients with early COVID-19 ( $n=129)$ and those who met the primary outcome ( $n=11$ ). I) Change in levels of 30 mediators from visit 1 (day 0 ) to visit 3 (day 14) of 1 patient who required critical care respiratory support (see supplement $\mathbf{S 6}$ for heatmap). Data were analysed using Mann-Whitney t-test, ${ }^{*}=p<0.05,{ }^{* *}=$ $p<0.01$ 


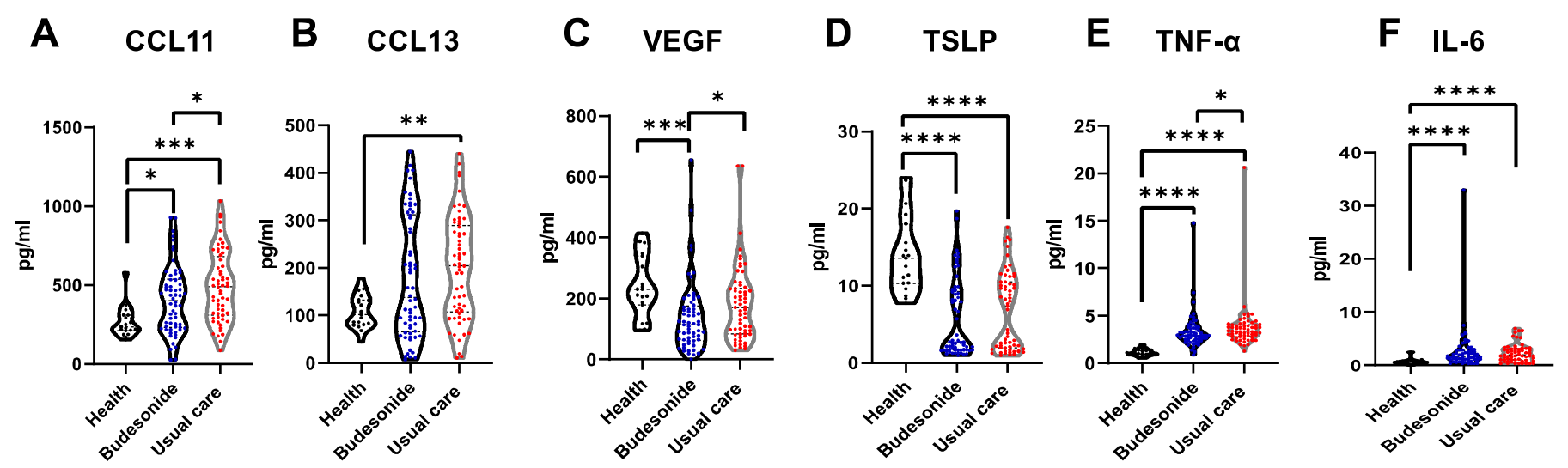

Figure 4. Persistence of systemic inflammation following 28-35 days of COVID-19 infection in the community, is dampened by inhaled budesonide. A-F) Violin plots comparing some mediator levels in the serum of healthy individuals $(n=19)$, those in the usual care arm $(n=60)$ and budesonide arm $(n=62)$ of the study at 28-35 days following COVID-19 infection (see supplement S7 for further results). Data were analysed by Kruskal-Wallis with post-hoc Dunn's test. * $\mathrm{p}<0.05,{ }^{* *} \mathrm{p}<0.01, * * * \mathrm{p}<0.001, * * * * \mathrm{p}<0.0001$ 


\section{A. Nasal mucosal inflammation}

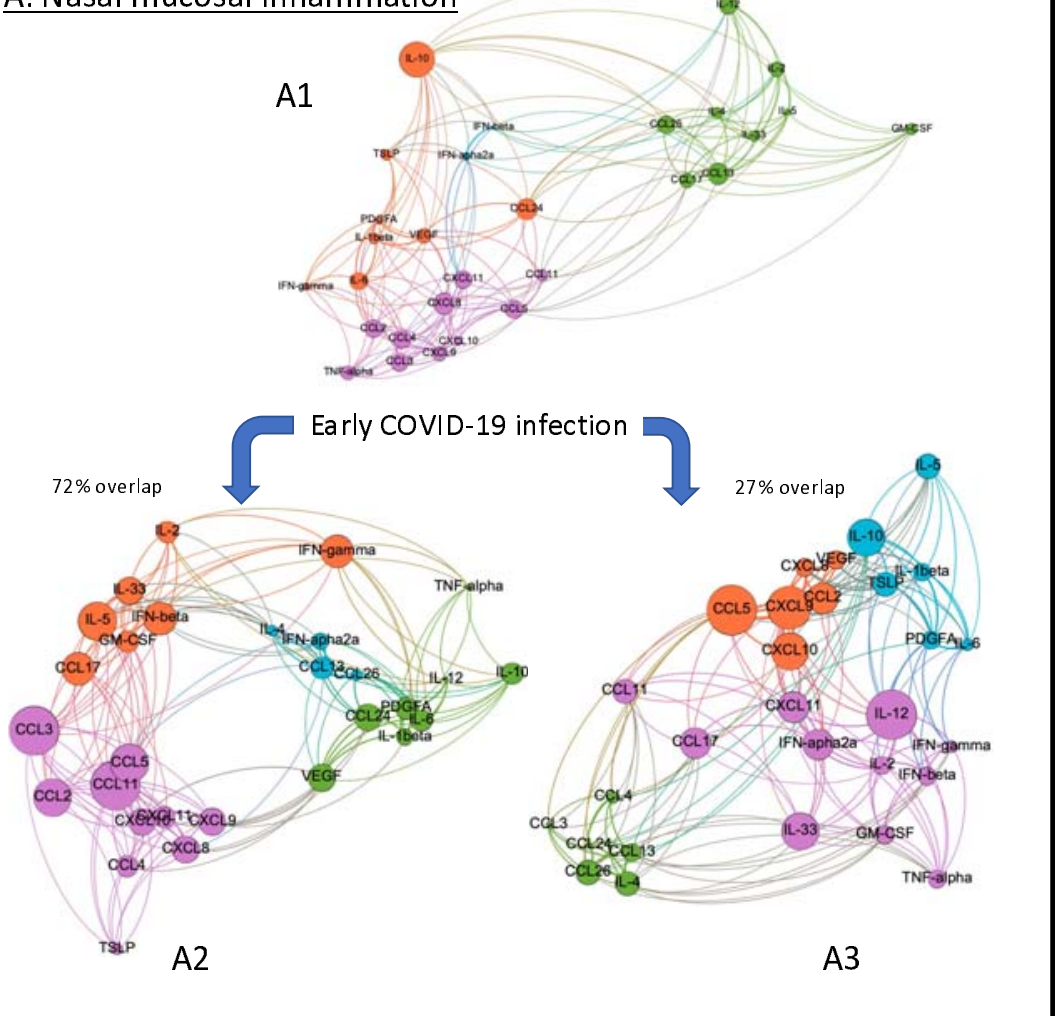

\section{B. Circulatory inflammation}

B1

B2
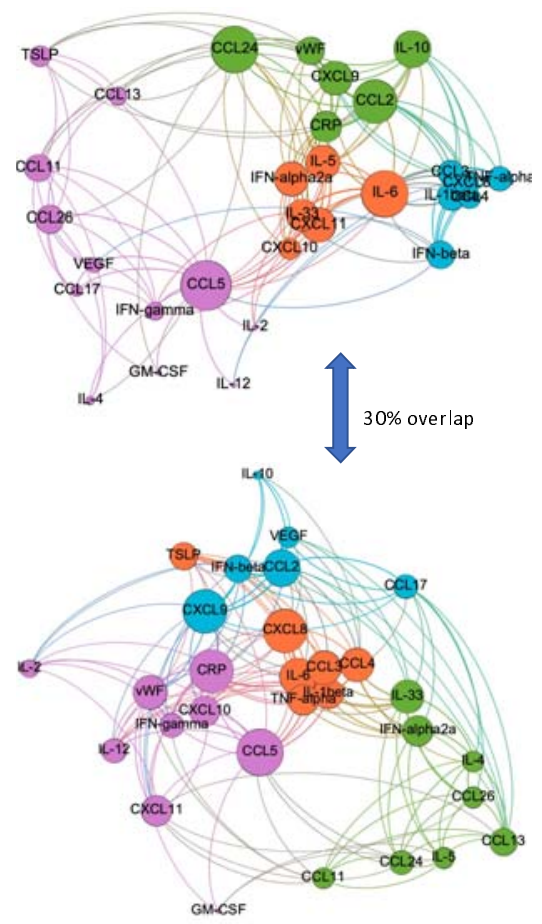

Figure 5. Network analysis of mediator correlation data. Panel A: Modularity maximisation and community detection for eigenvalue-based noise-cleaned nasal mucosal mediator data. Panel A1 corresponds to networks at initial COVID-19 infection; Panel A2 corresponds to networks after 14 days of initial COVID-19 infection; and Panel A3 corresponds to networks after treatment with inhaled budesonide. Node size indicates eigenvalue centrality and arcs indicate non-zero noise-cleaned correlation. In each network there are four modules, of roughly equal size. Panel A1 and A2 are similar with $72 \%$ overlap indicating persistent relationship of in flammation over time. Panel A1 and A3 have $27 \%$ overlap (which would be expected by a chance reassignment of nodes to the four modules) indicating that treatment with inhaled budesonide changes the inflammatory networks entirely. Panel B: Modularity maximisation and community detection for eigenvaluebased noise-cleaned serum data in participants from 28 to 35 days following COVID-19 infection. Panel B1 is network analysis of serum from participants in the usual care arm. Panel B2 is the network analysis of serum from participants in the budesonide arm. The two networks are entirely different in terms of membership with $30 \%$ overlap (equivalent to a random node reassignment to modules). This analysis is also consistent with a model in which budesonide treatment dramatically rearranges the mediator pathways in serum. 


\section{Methods}

\section{Study design and participants}

STOIC was a randomised, open-label, parallel group, phase 2 clinical intervention trial. Participants aged 18 and over with early COVID-19 symptoms (defined as new onset of cough and/or fever and/or anosmia for less than 7 days) were randomised to receive usual care (UC), namely as required anti-pyretics, or inhaled budesonide (BUD) at a dose of $800 \mu \mathrm{g}$ twice a day plus usual care (see supplement figure S1). Participants were seen at home at randomisation day 0 (visit 1), day 7 (visit 2), and day 14 (visit 3) by a research nurse to obtain consent, provide inhalers and collect nasal absorption samples and nasopharyngeal swabs which were self-performed. At day 28 (visit 4), whole blood was collected. Full details of study design, research protocols and clinical trial results are published $^{1}$. The study was approved by Fulham London Research Ethics Committee (20/HRA/2531) and the National Health Research Authority and was sponsored by the University of Oxford. All participants provided written informed consent.

\section{Healthy control participants}

Healthy controls were adults aged 18 and over, without any known history of lung disease or symptoms (including negative COVID-19 antigen tests) of COVID-19, recruited from a long-term observational data collection study at the University of Oxford (Ethics Ref 18/SC/0361).

\section{Nasal mucosal sampling}

Nasal mucosal sampling was self-performed by all participants as previously described ${ }^{37}$. Briefly, samples of the nasal mucosal lining fluid were collected by placing a Nasosorption ${ }^{\text {TM }}$ FX.I device (Hunt Developments UK Ltd) consisting of a synthetic absorptive matrix strip against the inferior turbinate for a duration of 1 minute. The sample was then eluted in $500 \mu \mathrm{L}$ of PBS, $1 \%$ bovine serum albumin (BSA) (w/v), 1\% Triton X-100 (v/v), and 0.05\% sodium azide (w/v) (Sigma-Aldrich, UK) and stored at $-80^{\circ} \mathrm{C}$.

\section{Isolation of serum}


Whole blood was collected into an SST tube (Fisher Scientific, Leicestershire, UK) and allowed to clot for $60 \mathrm{~min}$ at room temperature. The serum sample was then centrifuged at $3000 \times \mathrm{g}$ for $10 \mathrm{~min}$ at room temperature. Serum samples were then aliquoted and stored at $-80^{\circ} \mathrm{C}$.

\section{Virus extraction and quantification}

RNA was extracted using the QIAamp Viral RNA Mini Kit following manufacturer's instructions. Virologic testing for SARS-CoV-2 infection was performed by quantitative real-time RT-PCR (RTqPCR). Briefly, $420 \mu \mathrm{l}$ of sample was extracted and eluted into $40 \mu \mathrm{l}$ Buffer AVE. $10 \mu \mathrm{l}$ of eluted RNA was assayed using the Taqman fast virus 1-step master mix (ThermoFischer Scientific, Loughborough, UK), utilising oligonucleotide primers (600 nM forward and $800 \mathrm{nM}$ reverse per reaction) and fluorescent conjugated probes (two probes $100 \mathrm{nM}$ each) (Eurofins Genomics, Wolverhampton, UK) for the detection of the viral RNase P gene (RdRP) gene region of SARS-CoV-19. Quantification of virus RNA copies were generated using a standard curve using nCoV-WHO-Control plasmid of known concentration (Eurofins Genomics, Wolverhampton, UK).

\section{Immunoassays}

Immunoassays of mediators were selected to represent putative mechanistic inflammatory pathways associated with respiratory virus infections and thus COVID-19 $15,16,38$. Granulocyte macrophage-colony stimulating factor (GM-CSF), vascular endothelial growth factor (VEGF), tumour necrosis factor (TNF)- $\alpha$, interferon (IFN)- $\alpha 2 \mathrm{a}$, IFN- $\beta$, IFN- - , IL-33, thymic stromal lymphopoietin (TSLP), and interleukin (IL-)--1 $\beta$, IL-2, IL-4, IL-5, IL-6, CXCL8, IL-10, IL-12, CXCL10, CXCL11, CCL2, CCL3, CCL4, CCL13, CCL17, CCL11, CCL24 and CCL26 were quantified using MSD (Meso Scale Diagnostics, Rockville, Maryland, USA) 10 spot U-Plex plates. Transforming growth factor (TGF)- $\beta 1$, platelet derived growth factor (PDGF)-A, CXCL9, CCL5, von-Willebrand factor (VWF) and high-sensitivity C reactive protein ( $\mathrm{hSCRP}$ ) were measured by individual V-Plex plates, on a SQ120 Quickplex instrument (Meso Scale Diagnostics, Rockville, Maryland, USA). All values at or below the lower limit of detection (LLOD) or upper limit of detection (ULOD) were replaced by the LLOD or ULOD value as 
suggested by the assay parameters. Nasal mucosal mediators that were consistently around the ULOD were CXCL10 (6000 pg/ml) and CXCL8 (2100 pg/ml) whilst IFN- $\alpha 2 a(4 \mathrm{pg} / \mathrm{ml})$, CCL26 $(7.3$ $\mathrm{pg} / \mathrm{ml}), \mathrm{IL}-4(0.08 \mathrm{pg} / \mathrm{ml})$ and TGF- $\beta 1(9.1 \mathrm{pg} / \mathrm{ml})$ were around the LLOD.

\section{Statistical analysis}

Statistical analyses used GraphPad Prism v9.0.0 (GraphPad, La Jolla, California, USA). Spline analysis was calculated by correlating at mediator levels and time from symptom onset as previously described $^{39}$. Z-scores were calculated using the mean and standard deviation of all values dependent on analyses. Volcano plots were generated by calculating the -LOG10 of the P value change between healthy control and all visit 1 COVID-19 patients (un-paired analysis by Mann-Whitney) or visit 1 from the usual care study arm (UC) and budesonide study arm (BUD) against their paired visit 3 sample (paired analysis by Wilcoxon signed-rank test). Serum samples were analysed by KruskallWallis with post hoc Dunn's post-hoc multiple comparison test. Network analysis and visualisation software was developed in-house (code available on request) and is described below. For image rendering the Gephi package v0.9.2 (Gephi.org. The Open Graph Viz Platform) was used. P values $<0.05$ was considered statistically significant.

\section{Network analysis of inflammatory mediators}

To further elucidate the patterns of interactions between inflammatory mediators in COVID-19 both with and without inhaled budesonide treatment, we performed a mathematical analysis of the networks of mediators in various subsets of our data.

First, we computed correlation coefficients between mediator values in the nasal data across patients. For each of $M$ mediators, we have values for $n$ patients in either the BUD or UC arms. Regarding each patient index as an independent variable and each mediator value as a dependent variable, we can compute mediator-mediator expression correlation values, yielding an $m \times m$ matrix, with 1 s on the diagonal. 
This matrix represents a network with $m$ mediator nodes and whose entries correspond to the strength of mediator co-expression. In principle this network can be analysed as-is. However, it is known that correlations between data series containing measurement error contain as a result a large component of 'noise'. In particular, the eigenvalues of a rectangular matrix whose entries are random follow the Marchenko-Pastur distribution ${ }^{40}$. Therefore, those eigenvalues (and their associated eigenvectors) for an $m \times m$ correlation matrix falling within this distribution correspond to noise in the data and should be removed from the matrix. Specifically, the eigenvalues falling between the bounds

$$
\lambda_{ \pm}=\left(1 \pm \sqrt{\frac{m}{n}}\right)^{2}
$$

correspond to noise. In the types of correlation matrices analysed here (where $n$ is not much larger than $m$ ), most eigenvalues fall between these bounds (i.e., most of a correlation matrix is actually noise), confirming that analysing the original correlation networks directly would yield highly unreliable findings. By setting the noise eigenvalues to zero and reconstituting the matrix from the remaining non-zero (signal-associated) eigenvalues and their eigenvectors, we get an "eigencleaned" matrix, which can be used to perform network analysis on the co-expression of mediators (code available on request). We performed this procedure for the following data sets:

(1) Early COVID-19 infection at study enrolment (visit 1, baseline) for nasal mucosal inflammatory data

(2) BUD and UC arm analysis at visit 3 (14 days after randomisation) for nasal mucosal inflammatory data

(3) Serum mediator data for participants 28-35days after COVID-19 infection in the BUD and UC study arms respectively

This procedure results in 6 mediator-mediator co-expression networks. We split the analysis into the nasal and serum components. In the former case, we can look at how the visit 3 UC and BUD 
networks differed from the early COVID-19 baseline network, as well as from each other. In the latter case, we can compare the UC and BUD visit 3 networks with each other as well as with the healthy control network. We used modularity maximisation (code available on request) to detect communities (modules) within each of these networks. We chose the well-known Louvain algorithm for this analysis ${ }^{41}$ due to its robustness. Remarkably, in each of these networks, the algorithm detects four sub-modules that are highly internally connected and relatively unconnected from the other modules, of approximately equal size (4-8 mediators) confirming that there is substantial structure in mediator-mediator co-expression. However, the mediator membership assignment to the modules in each case varies substantially and, in particular, is altered by treatment with budesonide versus usual care.

\section{Acknowledgements}

The study was funded by the Oxford NIHR Biomedical Research Centre and AstraZeneca (Gothenburg Sweden). The funders had no role in study design, data collection, data analysis or the decision to publish. The views expressed are those of the authors and not necessarily those of the NHS, the NIHR or the Department of Health.

\section{Author contributions}

JRB, MM and SR were responsible for all sample collection, processing and analysis. JRB, DVN, PJB, JLS, SPC, REKR, LED and MB were responsible for data interpretation critical revision of the work. All authors contributed to this manuscript and were involved in the writing and approved the final submission.

\section{Competing interest declaration}

JRB, SPC, MM, DVN, and JSL have no competing interests to declare. SR reports grants and nonfinancial support from Oxford Respiratory NIHR BRC during the conduct of the study; non-financial support from AstraZeneca, personal fees from Australian Government Research Training Program 
medRxiv preprint doi: https://doi.org/10.1101/2021.10.26.21265512; this version posted October 27, 2021. The copyright holder for this preprint

(which was not certified by peer review) is the author/funder, who has granted medRxiv a license to display the preprint in perpetuity.

It is made available under a CC-BY-ND 4.0 International license .

outside the submitted work. LED reports grants from AstraZeneca, from Boehringer-Ingelheim, outside the submitted work. PJB reports grants and personal fees from AstraZeneca, grants and personal fees from Boehringer Ingelheim, personal fees from Teva, personal fees from Covis during the conduct of the study. REKR reports grants from AstraZeneca, personal fees from Boehringer Ingelheim, personal fees from Chiesi UK, personal fees from Glaxo-SmithKline during the conduct of the study. MB reports grants from AstraZeneca, personal fees from AstraZeneca, Chiesi, GSK, other from Albus Health, ProAxsis, outside the submitted work. 
medRxiv preprint doi: https://doi.org/10.1101/2021.10.26.21265512; this version posted October 27, 2021. The copyright holder for this preprint (which was not certified by peer review) is the author/funder, who has granted medRxiv a license to display the preprint in perpetuity.

$$
\text { It is made available under a CC-BY-ND } 4.0 \text { International license. }
$$

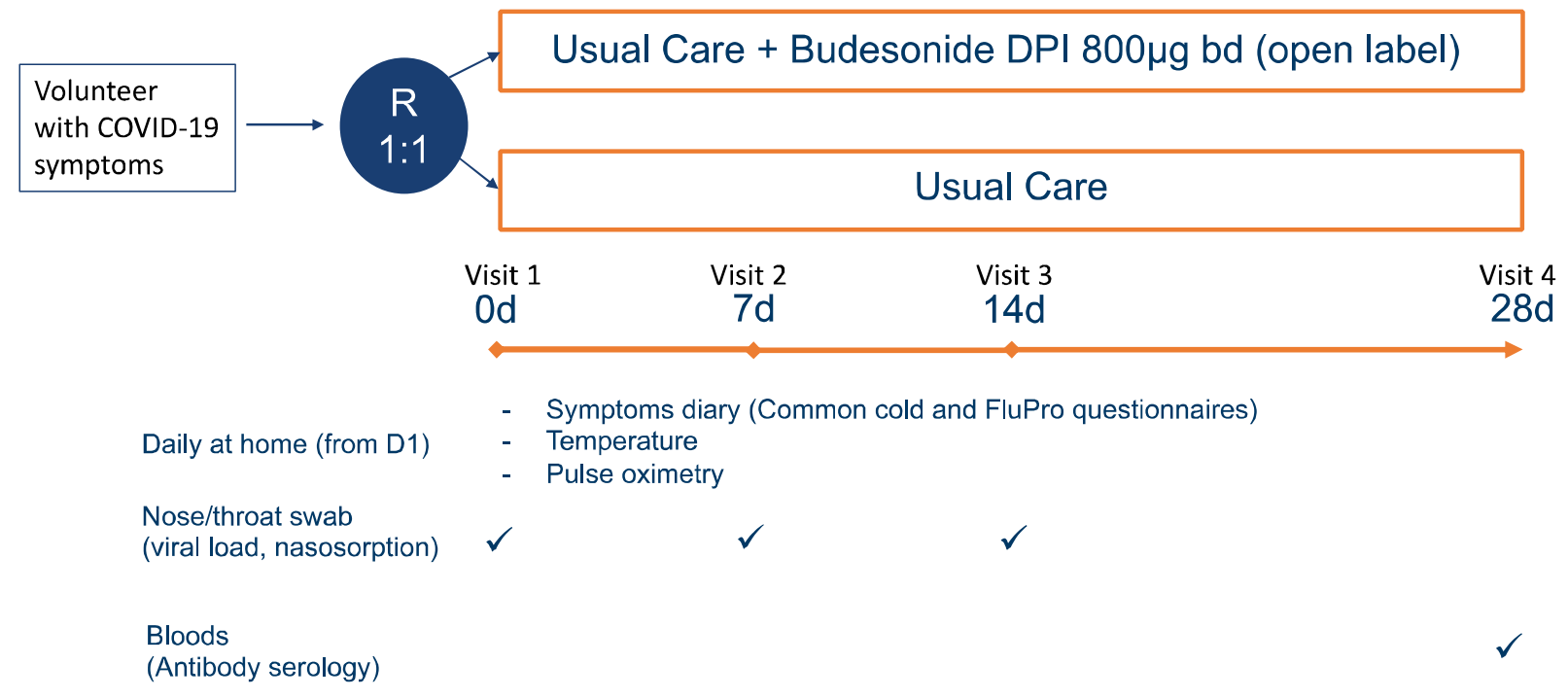

Supplementary figure S1. Study design schematic for the STOIC study. DPI Dry powdered inhaler;

bd (twice per day); d days 
medRxiv preprint doi: https://doi.org/10.1101/2021.10.26.21265512; this version posted October 27, 2021. The copyright holder for this preprint (which was not certified by peer review) is the author/funder, who has granted medRxiv a license to display the preprint in perpetuity. It is made available under a CC-BY-ND 4.0 International license.

A

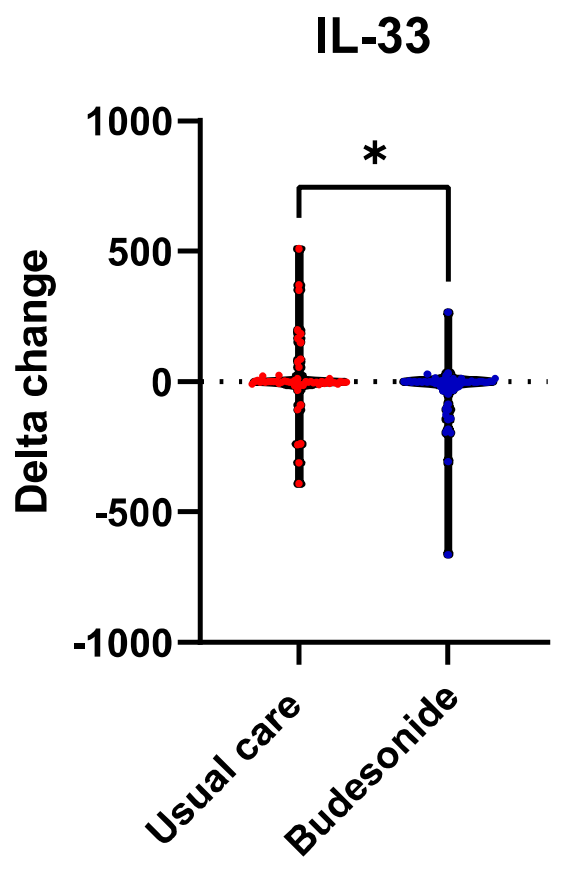

B

\section{CCL17}

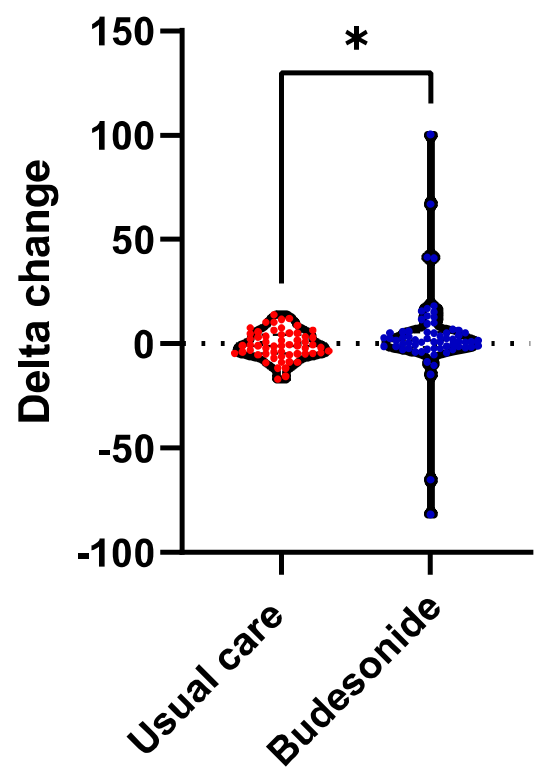


Figure S3

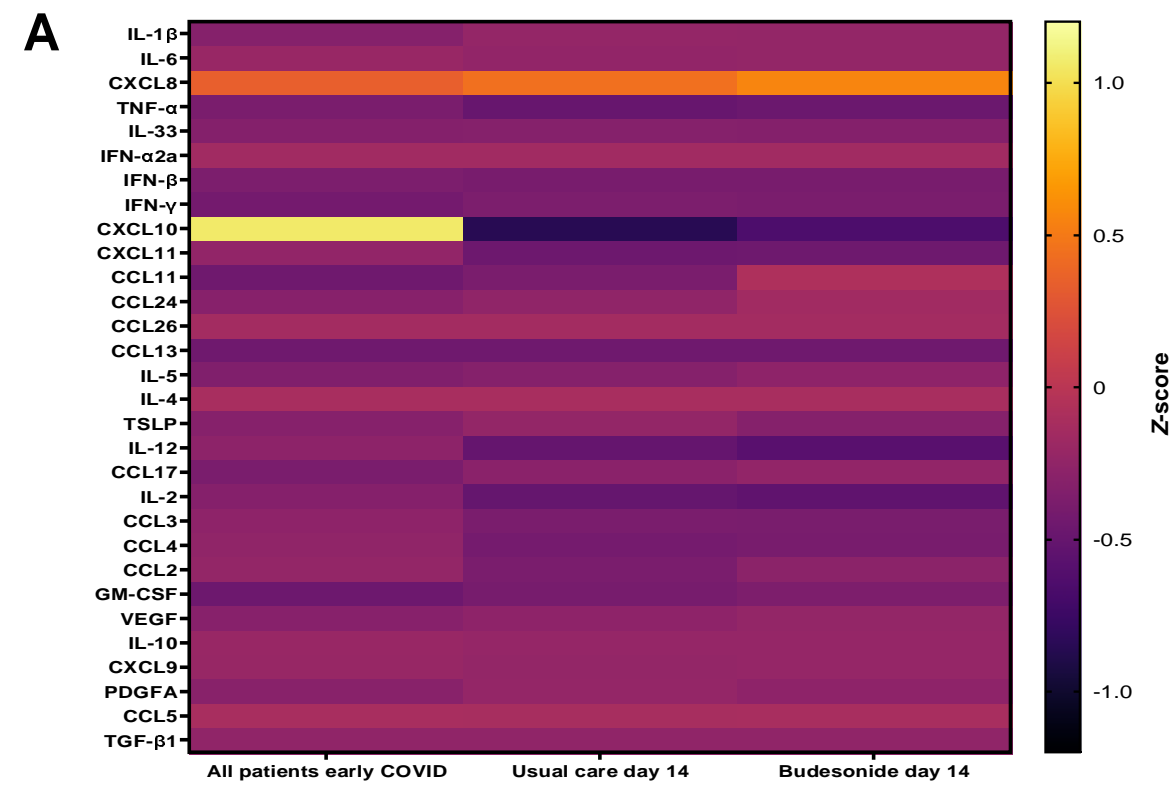

B

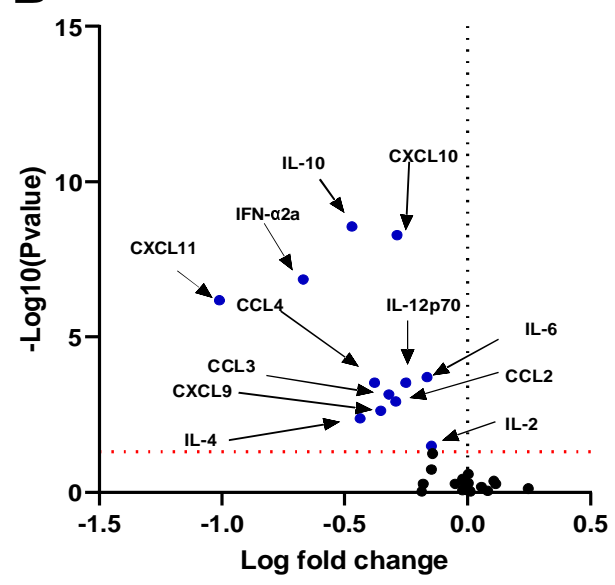

C

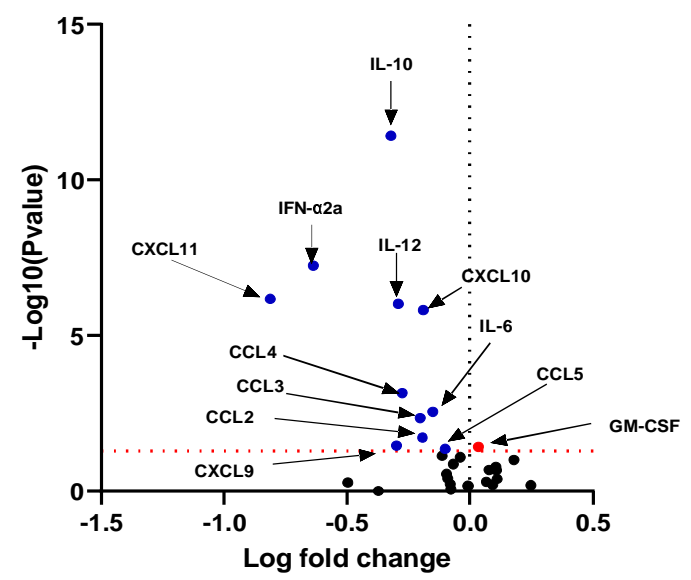

Supplementary figure S3. Difference in mediator levels between usual care and budesonide treatment compared to all early COVID-19 patients. A) A heatmap depicting changes in nasal mediators comparing levels in all visit 1 samples $(n=140)$ and visit 3 in usual care arm $(n=60)$ and budesonide arm ( $n=62)$. B) Volcano plot comparing all visit 1 samples to usual care visit 3. C) Volcano plot comparing all visit 1 samples to budesonide visit 3 . 圆= upregulated. ? $=$ downregulated. Data were analysed using Mann-Whitney t-test. 
Figure S4
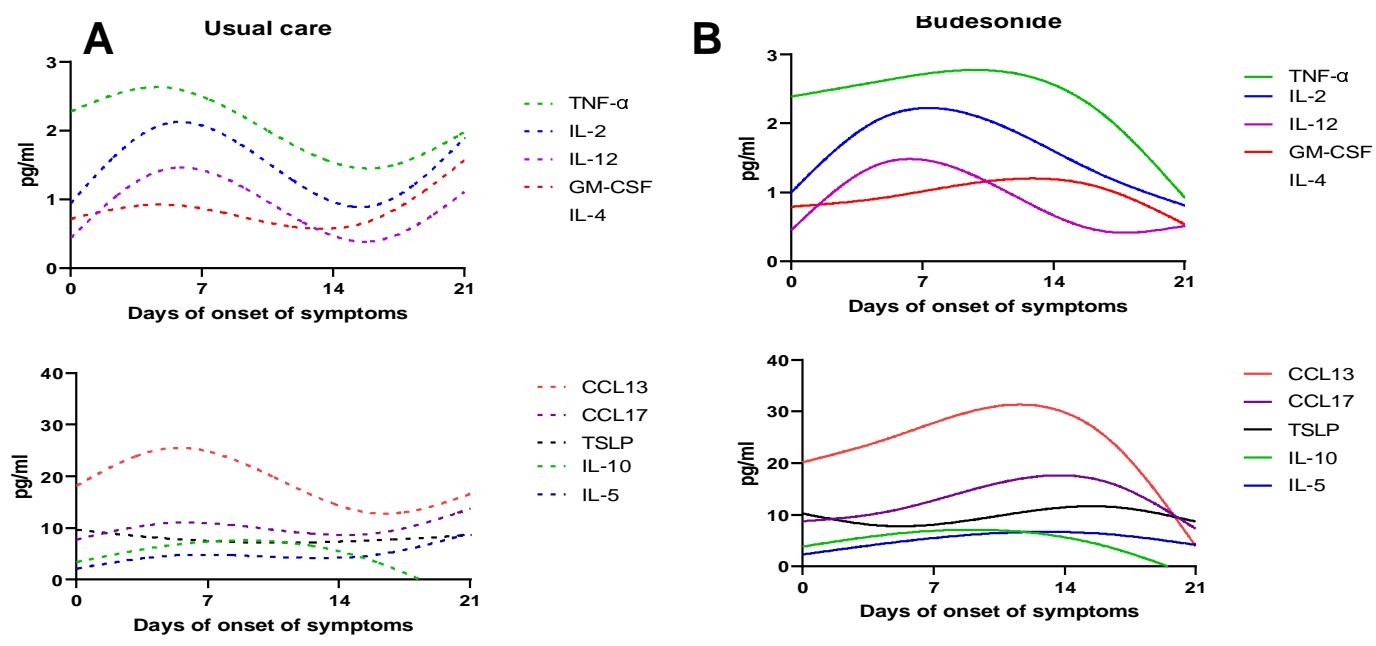

- . CCL13

- . CCL17

.. TSLP

. . IL-10
. . . IL-5

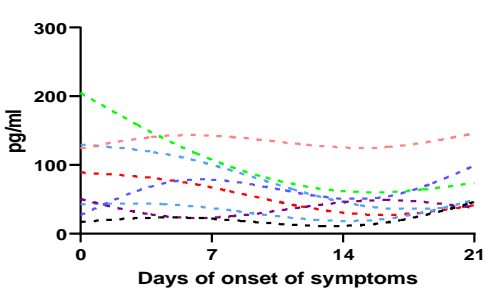

-. CCL11

- . CCL2

- - CCL3

-. CCL4

- . . IL-33

- . IL-33
- . IL-6

- . . IL-1ß

- . CCL26

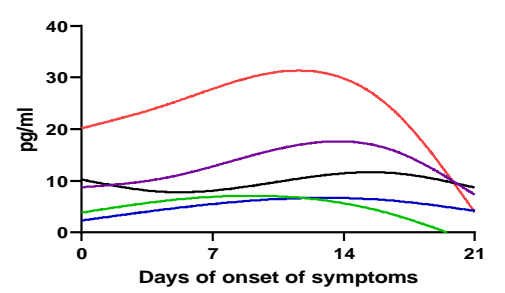

- $\mathrm{CCL} 13$

- CCL17

- TSLP

- IL-10

- IL-5

Days of onset of symptoms

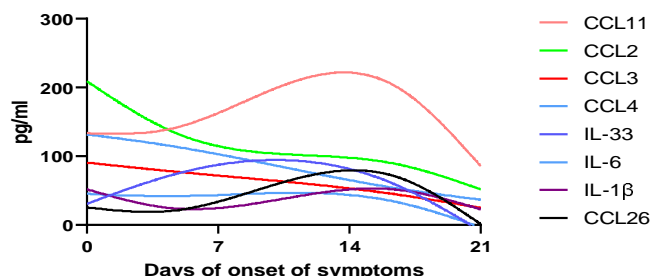

Days of onset of symptoms

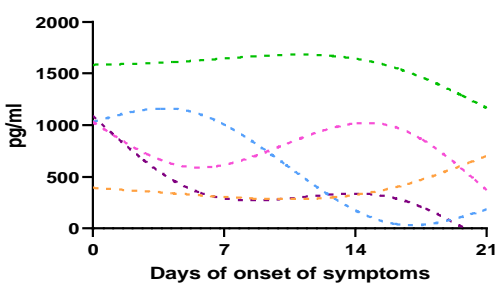

- . CXCL8

-. VEGF

-. CXCL9

CCL24

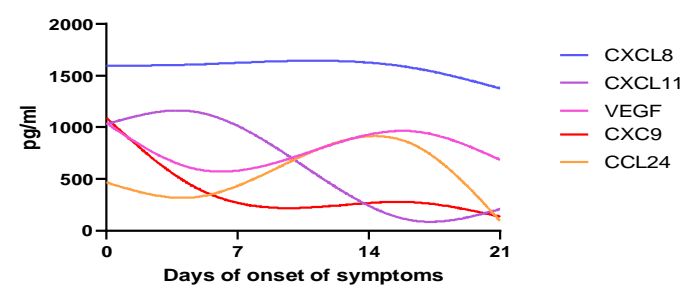

Supplementary figure S4. Spline analysis of nasal mucosal mediator levels from first symptom

onset. Longitudinal analysis of mediator profiles in the A) usual care $(n=60)$ and B) budesonide arm $(n=62)$ displayed as representative best fit curves by smoothed spline analysis. 
medRxiv preprint doi: https://doi.org/10.1101/2021.10.26.21265512; this version posted October 27, 2021. The copyright holder for this preprint (which was not certified by peer review) is the author/funder, who has granted medRxiv a license to display the preprint in perpetuity.

\section{It is made available under a CC-BY-ND 4.0 International license.}

\section{Figure S5}
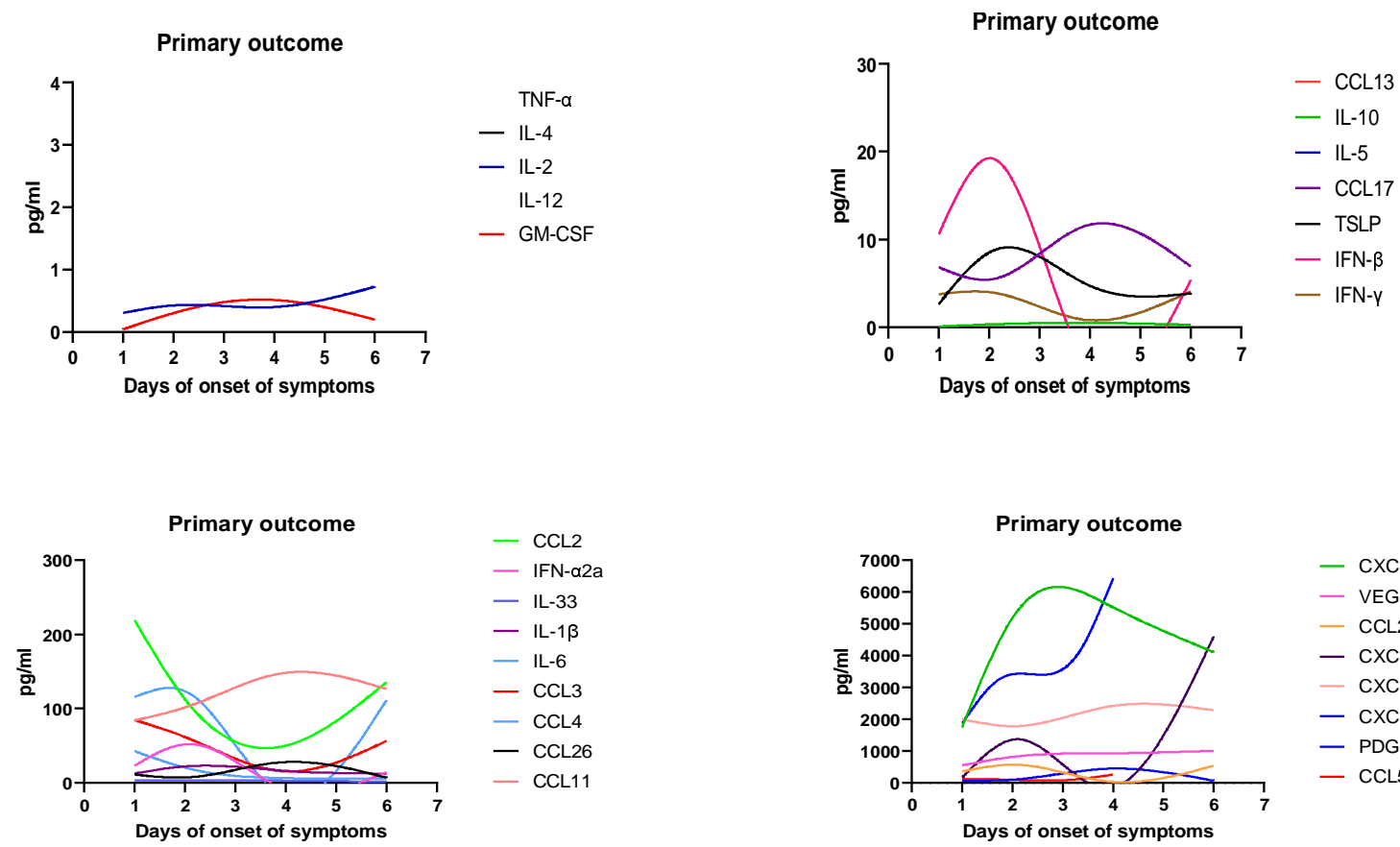

$$
\begin{aligned}
& \text { - } \mathrm{CCL2} \\
& -\mathrm{IFN}-\alpha 2 \mathrm{a} \\
& -\mathrm{IL}-33 \\
& -\mathrm{IL}-1 \beta \\
& -\mathrm{IL}-6 \\
& -\mathrm{CCL} 3 \\
& -\mathrm{CCL} 4 \\
& -\mathrm{CCL} 26 \\
& \text { - CCL11 }
\end{aligned}
$$

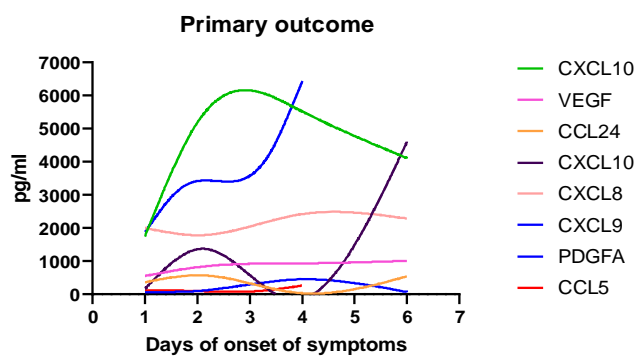

Supplementary figure S5. Spline analysis of nasal mucosal mediator levels from first symptom onset in participants who reached the primary outcome $(n=11)$. 
medRxiv preprint doi: https://doi.org/10.1101/2021.10.26.21265512; this version posted October 27, 2021. The copyright holder for this preprint (which was not certified by peer review) is the author/funder, who has granted medRxiv a license to display the preprint in perpetuity.

\section{It is made available under a CC-BY-ND 4.0 International license .}

Figure S6

A

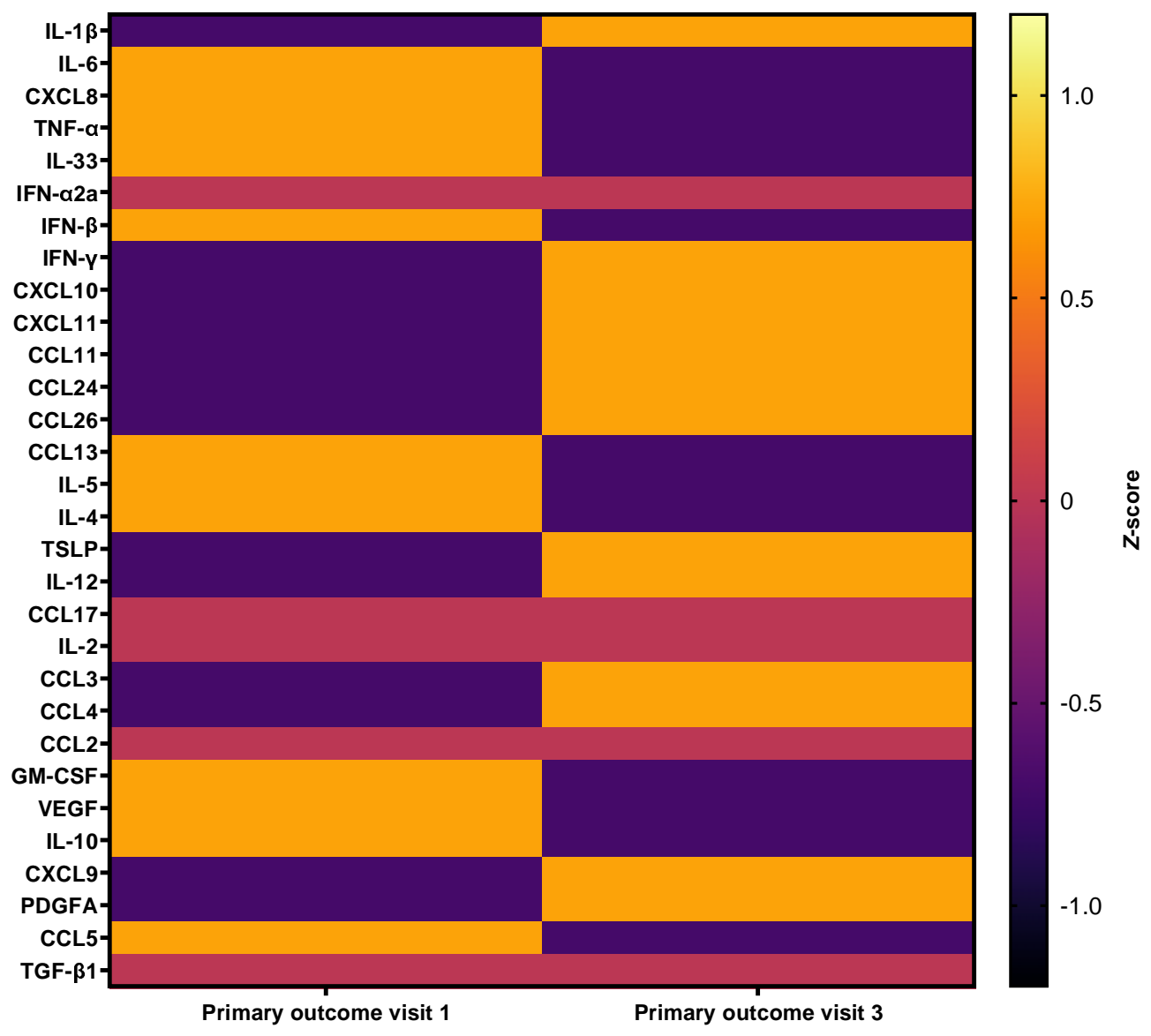

Supplementary figure S6. Heatmap for one patient who developed severe COVID-19 infection and met the study primary outcome who gave two nasal samples. 
Figure S7
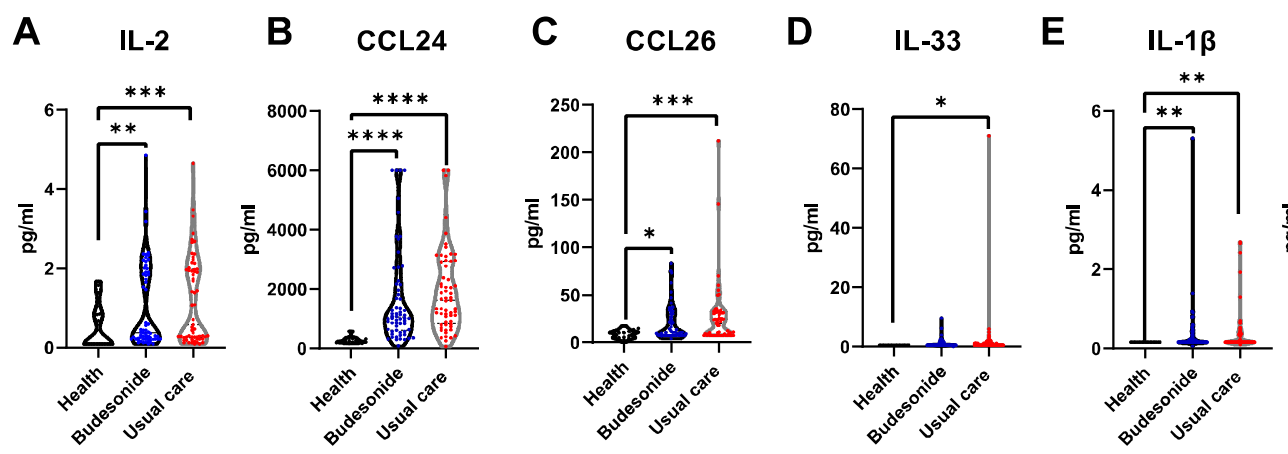

F CXCL8

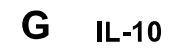

H CXCL10
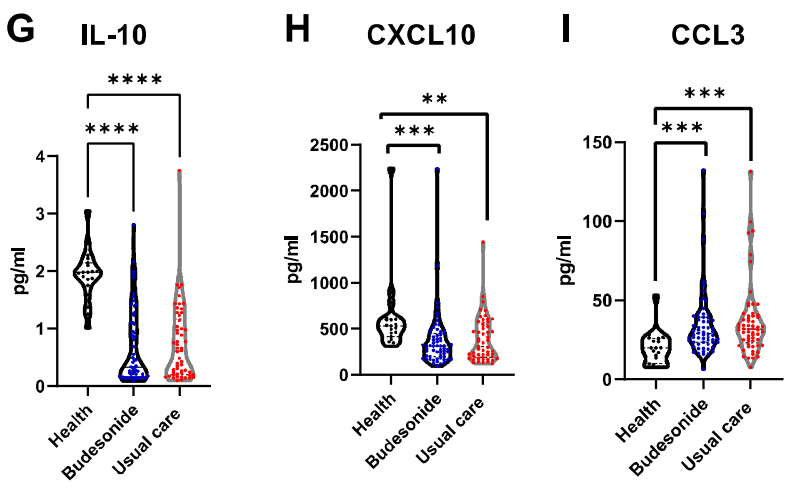

COVID-19 infection. A-I) Violin plots comparing mediator levels in the serum of healthy individuals $(n=19)$, those in the usual care arm $(n=60)$ and budesonide arm $(n=62)$ of the study at 28 days post recruitment. Data were analysed by Kruskal-Wallis with post-hoc Dunn's test. ${ }^{*} p<0.05,{ }^{* *} p<0.01$, $* * * p<0.001, * * * p<0.0001$. 
medRxiv preprint doi: https://doi.org/10.1101/2021.10.26.21265512; this version posted October 27, 2021. The copyright holder for this preprint (which was not certified by peer review) is the author/funder, who has granted medRxiv a license to display the preprint in perpetuity.

It is made available under a CC-BY-ND 4.0 International license .

\section{Extended Data Supplementary Tables}

S1 Demographic table of healthy controls

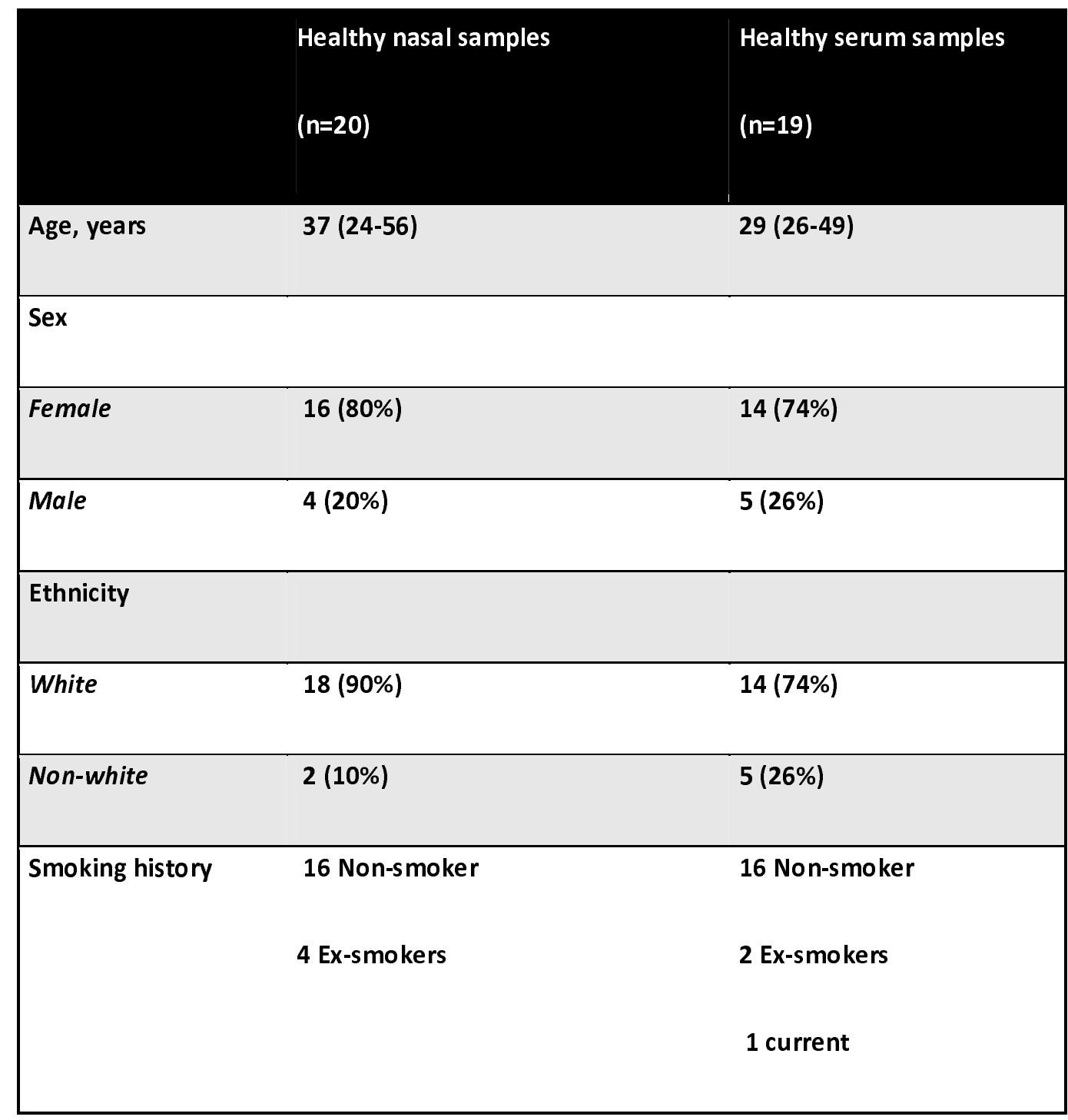


medRxiv preprint doi: https://doi.org/10.1101/2021.10.26.21265512; this version posted October 27, 2021. The copyright holder for this preprint (which was not certified by peer review) is the author/funder, who has granted medRxiv a license to display the preprint in perpetuity. It is made available under a CC-BY-ND 4.0 International license .

Supplementary Table 2. Correlation between nasal mediators and viral load. Two tailed Spearman rank correlations with $95 \%$ confidence intervals between viral load and individual mediator levels at visit 1 for those that gave both a viral swab and nasosorption sample ( $n=122)$. A). Only positively correlated mediated depicted. ${ }^{* *}=p<0.01,{ }^{*}=p<0.05$.

\begin{tabular}{|c|c|c|c|c|c|c|}
\hline & $\begin{array}{c}\text { Viral titre } \\
\text { vs. } \\
\text { IL-12 }\end{array}$ & $\begin{array}{c}\text { Viral titre } \\
\text { vs. } \\
\text { CXCL10 }\end{array}$ & $\begin{array}{c}\text { Viral titre } \\
\text { vs. } \\
\text { CCL2 }\end{array}$ & $\begin{array}{c}\text { Viral titre } \\
\text { vs. } \\
\text { CXCL11 }\end{array}$ & $\begin{array}{c}\text { Viral titre } \\
\text { vs. } \\
\text { IFN- } \alpha 2 a\end{array}$ & $\begin{array}{c}\text { Viral titre } \\
\text { vs. } \\
\text { IL-6 }\end{array}$ \\
\hline $\begin{array}{c}\text { Spearman } \\
\mathbf{r} \\
\end{array}$ & 0.2540 & 0.2443 & 0.2462 & 0.2373 & 0.2242 & 0.2241 \\
\hline $\begin{array}{c}95 \% \text { confidence } \\
\text { interval }\end{array}$ & $\begin{array}{c}0.07454 \text { to } \\
0.4175\end{array}$ & $\begin{array}{c}0.06428 \text { to } \\
0.4089\end{array}$ & $\begin{array}{c}0.06626 \text { to } \\
0.4106\end{array}$ & $\begin{array}{c}0.05688 \text { to } \\
0.4027\end{array}$ & $\begin{array}{c}0.04308 \text { to } \\
0.3911\end{array}$ & $\begin{array}{c}0.04300 \text { to } \\
0.3910\end{array}$ \\
\hline P (two-tailed) & 0.0048 & 0.0067 & 0.0063 & 0.0085 & 0.0130 & 0.0131 \\
\hline $\begin{array}{c}\text { P value } \\
\text { summary }\end{array}$ & $\star \star$ & ** & $\star \star$ & ** & * & * \\
\hline
\end{tabular}


medRxiv preprint doi: https://doi.org/10.1101/2021.10.26.21265512; this version posted October 27, 2021. The copyright holder for this preprint (which was not certified by peer review) is the author/funder, who has granted medRxiv a license to display the preprint in perpetuity.

It is made available under a CC-BY-ND 4.0 International license .

\section{References}

1 Ramakrishnan, S. et al. Inhaled budesonide in the treatment of early COVID-19 (STOIC): a phase 2, open-label, randomised controlled trial. Lancet Respir Med, doi:10.1016/s22132600(21)00160-0 (2021).

2 Yu, L. M. et al. Inhaled budesonide for COVID-19 in people at high risk of complications in the community in the UK (PRINCIPLE): a randomised, controlled, open-label, adaptive platform trial. Lancet 398, 843-855, doi:10.1016/S0140-6736(21)01744-X (2021). Leist, S. R., Schäfer, A. \& Martinez, D. R. Cell and animal models of SARS-CoV-2 pathogenesis and immunity. Disease Models \& Mechanisms 13, doi:10.1242/dmm.046581 (2020). Peluso, M. J. et al. Long-term SARS-CoV-2-specific immune and inflammatory responses in individuals recovering from COVID-19 with and without post-acute symptoms. Cell Rep 36, 109518, doi:10.1016/j.celrep.2021.109518 (2021). Farr, R. J. et al. Altered microRNA expression in COVID-19 patients enables identification of SARS-CoV-2 infection. PLoS Pathog 17, e1009759, doi:10.1371/journal.ppat.1009759 (2021). Rouse, B. T. \& Sehrawat, S. Immunity and immunopathology to viruses: what decides the outcome? Nature Reviews Immunology 10, 514-526, doi:10.1038/n ri2802 (2010). Message, S. D. \& Johnston, S. L. The immunology of virus infection in asthma. European Respiratory Journal 18, 1013, doi:10.1183/09031936.01.00228701 (2001). Guo-Parke, H., Linden, D., Weldon, S., Kidney, J. C. \& Taggart, C. C. Mechanisms of VirusInduced Airway Immunity Dysfunction in the Pathogenesis of COPD Disease, Progression, and Exacerbation. Frontiers in Immunology 11, doi:10.3389/fimmu.2020.01205 (2020). Tan, W. C. Viruses in asthma exacerbations. Curr Opin Pulm Med 11, 21-26, doi:10.1097/01.mcp.0000146781.11092.0d (2005).

10 Papi, A. et al. Infections and airway inflammation in chronic obstructive pulmonary disease severe exacerbations. Am J Respir Crit Care Med 173, 1114-1121, doi:10.1164/rccm.200506$8590 C$ (2006).

11 Bafadhel, M. et al. Acute exacerbations of chronic obstructive pulmonary disease: identification of biologic clusters and their biomarkers. Am J Respir Crit Care Med 184, 662671, doi:10.1164/rccm.201104-05970C (2011).

12 Guan, W. J. et al. Comorbidity and its impact on 1590 patients with COVID-19 in China: a nationwide analysis. Eur Respir J 55, doi:10.1183/13993003.00547-2020 (2020).

13 Rogliani, P., Lauro, D., Di Daniele, N., Chetta, A. \& Calzetta, L. Reduced risk of COVID-19 hospitalization in asthmatic and COPD patients: a benefit of inhaled corticosteroids? Expert Rev Respir Med 15, 561-568, doi:10.1080/17476348.2021.1850275 (2021).

14 Bloom, C. I. et al. Risk of adverse outcomes in patients with underlying respiratory conditions admitted to hospital with COVID-19: a national, multicentre prospective cohort study using the ISARIC WHO Clinical Characterisation Protocol UK. Lancet Respir Med, doi:10.1016/S2213-2600(21)00013-8 (2021).

15 Morton, B. et al. Distinct clinical and immunological profiles of patients with evidence of SARS-CoV-2 infection in sub-Saharan Africa. Nature communications 12, 3554, doi:10.1038/s41467-021-23267-w (2021).

16 Lucas, C. et al. Longitudinal analyses reveal immunological misfiring in severe COVID-19. Nature 584, 463-469, doi:10.1038/s41586-020-2588-y (2020).

17 Liao, M. et al. Single-cell landscape of bronchoalveolar immune cells in patients with COVID19. Nature Medicine 26, 842-844, doi:10.1038/s41591-020-0901-9 (2020).

18 Chua, R. L. et al. COVID-19 severity correlates with airway epithelium-immune cell interactions identified by single-cell analysis. Nature Biotechnology 38, 970-979, doi:10.1038/s41587-020-0602-4 (2020). 
medRxiv preprint doi: https://doi.org/10.1101/2021.10.26.21265512; this version posted October 27, 2021. The copyright holder for this preprint (which was not certified by peer review) is the author/funder, who has granted medRxiv a license to display the preprint in perpetuity.

It is made available under a CC-BY-ND 4.0 International license .

19 Han, H. et al. Profiling serum cytokines in COVID-19 patients reveals IL-6 and IL-10 are disease severity predictors. Emerging Microbes \& Infections 9, 1123-1130, doi:10.1080/22221751.2020.1770129 (2020).

20 Mason, R. J. Thoughts on the alveolar phase of COVID-19. American Journal of PhysiologyLung Cellular and Molecular Physiology 319, L115-L120, doi:10.1152/ajplung.00126.2020 (2020).

21 Vareille, M., Kieninger, E., Edwards, M. R. \& Regamey, N. The airway epithelium: soldier in the fight against respiratory viruses. Clin Microbiol Rev 24, 210-229, doi:10.1128/CMR.00014-10 (2011).

22 Hadjadj, J. et al. Impaired type I interferon activity and inflammatory responses in severe COVID-19 patients. Science 369, 718-724, doi:10.1126/science.abc6027 (2020).

23 Gleich, G. J. Mechanisms of eosinophil-associated inflammation. J Allergy Clin Immunol 105, 651-663, doi:10.1067/mai.2000.105712 (2000).

24 Zhou, F. et al. Clinical course and risk factors for mortality of adult inpatients with COVID-19 in Wuhan, China: a retrospective cohort study. Lancet 395, 1054-1062, doi:10.1016/S01406736(20)30566-3 (2020).

25 Bafadhel, M., Pavord, I. D. \& Russell, R. E. K. Eosinophils in COPD: just another biomarker? Lancet Respir Med 5, 747-759, doi:10.1016/S2213-2600(17)30217-5 (2017).

26 Iyengar, K. P., Jain, V. K., Vaishya, R. \& Ish, P. Long COVID-19: an emerging pandemic in itself. Adv Respir Med 89, 234-236, doi:10.5603/ARM.a2021.0040 (2021).

27 Saris, A. et al. Distinct cellular immune profiles in the airways and blood of critically ill patients with COVID-19. Thorax 76, 1010, doi:10.1136/thoraxjnl-2020-216256 (2021).

28 Sudre, C. H. et al. Attributes and predictors of long COVID. Nature Medicine 27, 626-631, doi:10.1038/s41591-021-01292-y (2021).

29 Lee, A. J. \& Ashkar, A. A. The Dual Nature of Type I and Type II Interferons. Frontiers in Immunology 9, doi:10.3389/fimmu.2018.02061 (2018).

30 Murira, A. \& Lamarre, A. Type-I Interferon Responses: From Friend to Foe in the Battle against Chronic Viral Infection. Frontiers in Immunology 7, doi:10.3389/fimmu.2016.00609 (2016).

31 Hoffmann, M. et al. SARS-CoV-2 Cell Entry Depends on ACE2 and TMPRSS2 and Is Blocked by a Clinically Proven Protease Inhibitor. Cell 181, 271-280 e278, doi:10.1016/j.cell.2020.02.052 (2020).

32 Finney, L. J. et al. Inhaled corticosteroids downregulate the SARS-CoV-2 receptor ACE2 in COPD through suppression of type I interferon. The Journal of allergy and clinical immunology 147, 510-519 e515, doi:10.1016/j.jaci.2020.09.034 (2021).

33 Milne, S. et al. Inhaled corticosteroids downregulate SARS-CoV-2-related genes in COPD: results from a randomised controlled trial. Eur Respir J 58, doi:10.1183/13993003.001302021 (2021).

34 Yamaya, M., Nishimura, H., Nadine, L., Kubo, H. \& Nagatomi, R. Formoterol and budesonide inhibit rhinovirus infection and cytokine production in primary cultures of human tracheal epithelial cells. Respir Investig 52, 251-260, doi:10.1016/j.resinv.2014.03.004 (2014).

35 Barnes, P. J. Inhaled Corticosteroids. Pharmaceuticals (Basel) 3, 514-540, doi:10.3390/ph3030514 (2010).

36 Scheller, J., Chalaris, A., Garbers, C. \& Rose-John, S. ADAM17: a molecular switch to control inflammation and tissue regeneration. Trends in Immunology 32, 380-387, doi:https://doi.org/10.1016/i.it.2011.05.005 (2011).

37 Thwaites, R. S. et al. Absorption of Nasal and Bronchial Fluids: Precision Sampling of the Human Respiratory Mucosa and Laboratory Processing of Samples. J Vis Exp, doi:10.3791/56413 (2018). 
medRxiv preprint doi: https://doi.org/10.1101/2021.10.26.21265512; this version posted October 27, 2021. The copyright holder for this preprint

(which was not certified by peer review) is the author/funder, who has granted medRxiv a license to display the preprint in perpetuity.

It is made available under a CC-BY-ND 4.0 International license .

38 Thwaites, R. S. et al. Inflammatory profiles across the spectrum of disease reveal a distinct role for GM-CSF in severe COVID-19. Sci Immunol 6, doi:10.1126/sciimmunol.abg9873

(2021).

39 Del Valle, D. M. et al. An inflammatory cytokine signature predicts COVID-19 severity and survival. Nature medicine 26, 1636-1643, doi:10.1038/s41591-020-1051-9 (2020).

40 Marchenko, V. A. \& Pastur, L. A. Распределение собственных значений в некоторых ансамблях случайных матриц" [Distribution of eigenvalues for some sets of random matrices]. Mat. Sb. 72, 507-536 (1967).

41 Blondel, V. D., Guillaume, J.-L., Lambiotte, R. \& Lefebvre, E. Fast unfolding of communities in large networks. Journal of Statistical Mechanics: Theory and Experiment 2008, P10008, doi:10.1088/1742-5468/2008/10/p10008 (2008). 